\title{
New frontiers in oncolytic viruses: optimizing and selecting for virus strains with improved efficacy
}

This article was published in the following Dove Press journal:

Biologics:Targets and Therapy

\author{
Kenneth Lundstrom \\ PanTherapeutics, Lutry, Switzerland
}

Correspondence: Kenneth Lundstrom PanTherapeutics, 49 Route de Lavaux, Lutry CHI 095, Switzerland

Tel +4I 79776635 I

Email lundstromkenneth@gmail.com

\begin{abstract}
Oncolytic viruses have demonstrated selective replication and killing of tumor cells. Different types of oncolytic viruses - adenoviruses, alphaviruses, herpes simplex viruses, Newcastle disease viruses, rhabdoviruses, Coxsackie viruses, and vaccinia viruses - have been applied as either naturally occurring or engineered vectors. Numerous studies in animal-tumor models have demonstrated substantial tumor regression and prolonged survival rates. Moreover, clinical trials have confirmed good safety profiles and therapeutic efficacy for oncolytic viruses. Most encouragingly, the first cancer gene-therapy drug - Gendicine, based on oncolytic adenovirus type 5 - was approved in China. Likewise, a second-generation oncolytic herpes simplex virus-based drug for the treatment of melanoma has been registered in the US and Europe as talimogene laherparepvec.
\end{abstract}

Keywords: immunotherapy, viral vectors, clinical trials, drug approval

\section{Introduction}

Gene-therapy applications were initiated in the 1990s by utilization of both nonviral and viral delivery vectors. ${ }^{1}$ Although some progress was seen early on, the whole field, especially the utilization of viral vectors, was severely hampered by some setbacks. Particularly, the death of a young patient treated with adenovirus vectors for the nonlife-threatening disease ornithine transcarbamylase ${ }^{2}$ significantly reduced the interest in gene therapy and slowed down its progress. Furthermore, retrovirus vectors used for treatment of children suffering from severe combined immunodeficiency (SCID) showed integration of a therapeutic gene into the $L M O 2$ proto-oncogene region, which triggered leukemia development in some patients. ${ }^{3,4}$ In hindsight, it is obviously easy to criticize the scientific community for moving too quickly into clinical trials without the proper safety conditions established. The setbacks, however, forced some serious reengineering of viral vectors and clinical protocols to improve delivery and targeting and to meet appropriate safety standards. These modifications include the introduction of elements controlling replication and expression, as well as means of termination of virus propagation by addition of the prodrug ganciclovir after administration of replication-competent Sindbis virus (SINV) carrying a fusion of the herpes simplex virus (HSV) TK gene and the SINV protein nsP3. ${ }^{5}$ In the long run, vector engineering has significantly improved the properties of second- and third-generation vectors and enabled their safe applications for the treatment of various diseases. ${ }^{6}$

In this review, the focus is entirely on viral vectors in cancer therapy. One of the key issues from the birth of gene therapy has been delivery, and it remains the talking 
point. ${ }^{1}$ Intensive vector engineering addressing targeting and delivery by the introduction of target-specific recognition signals and/or delivery-enhancing molecules, such as polymers and liposomes, has contributed to increased efficacy. Furthermore, the design of packaging cell lines has significantly facilitated the utilization of viral vectors for cancer treatment in experimental animal models. An interesting approach comprises employing oncolytic viruses as both naturally occurring ${ }^{7}$ and engineered ${ }^{8}$ vectors can provide superior therapeutic efficacy, due to their selective tumor cell-killing capacity and potential induction of systemic antitumor immunity. ${ }^{9}$ Today, a number of different oncolytic viruses, such as adenoviruses (Ads) $,{ }^{10} \mathrm{HSV},{ }^{11}$ alphaviruses, rhabdoviruses, ${ }^{12}$ Newcastle disease virus (NDV), ${ }^{13}$ vaccinia viruses (VVs) ${ }^{14}$ and others have been evaluated for antitumor activity in a number of animal models and in clinical trials.

\section{Viral vectors desirable for therapeutic strategies}

Commonly, both nonviral and viral vectors have been applied in cancer therapy. ${ }^{1}$ The use of nonviral vectors has mainly been favored by their straightforward application and generally good safety profiles, while the attractive features of viral vectors relate to their ability to provide superior delivery and extreme levels of transgene expression. Viral vectors have in general been characterized by their broad range of hostcell tropism and extreme expression levels of heterologous genes. ${ }^{15}$ Transient high-level expression is especially attractive for cancer-therapy applications, as the presence of antitumor and/or toxic products is limited in time. Alternatively, expression vectors comprised of regulation and termination signals have been engineered to restrict vector spread and long-term toxicity. Generally, viral vectors carrying either a DNA or RNA genome can accommodate foreign genetic information of different sizes, depending on which type of viral vector is used. ${ }^{15}$ For instance, vectors based on HSV and $\mathrm{VV}$ are capable of accommodating more than $30 \mathrm{~kb}$ of foreign DNA, whereas most vector systems allow packaging of 6-8 $\mathrm{kb}$ of inserts, which is sufficient for covering more or less any therapeutic gene. Only adenoassociated viruses (AAVs) show a somewhat-limited packaging capacity in the range of $4 \mathrm{~kb}$, but even that allows accommodation of a wide range of appropriate therapeutic genes. Both replication-deficient and -competent viral particles have been applied in immunization and therapeutic interventions in animal models. ${ }^{15}$ Moreover, alphavirus vectors have been utilized in the form of naked RNA and plasmid DNA for the delivery of therapeutic genetic information for toxic, anticancer, and immunostimulatory genes, as well as for miRNA and shRNA ${ }^{16}$.

Another issue is the potential immunogenicity triggered by the administration of viral vectors. In this context, the original Ad vectors have demonstrated strong immunogenicity, although later-generation versions with gene deletions have proven to be less immunogenic. ${ }^{17} \mathrm{AAV}$ vectors have also shown strong immunogenicity, especially after virus readministration, which has been circumvented by using different AAV serotypes for subsequent injections. ${ }^{18}$

The discovery of oncolytic viruses, which can provide specific replication in tumor cells and further induce killing without affecting normal cells, has provided attractive alternative opportunities for cancer-therapy applications. In this context, naturally occurring oncolytic viruses and genetically engineered vectors have been subjected to cancer therapy and cancer-vaccine studies in animal models (Table 1), as described in detail herein ("Examples of therapeutic applications of oncolytic viruses" section).

\section{Mechanisms of oncolytic activity}

Both natural and engineered oncolytic viruses utilize the general routes of recognition of cell-surface receptors and fusion to the plasma membrane with the special capability of establishing a lytic cycle in malignant cells, while normal tissues remain unaffected. ${ }^{19,20}$ The mechanism of action occurs through RAS-pathway activation or by genetic modifications. ${ }^{21,22}$ In this context, HSV has been demonstrated to replicate only in tumor cells dependent on TK activity. ${ }^{23}$ Moreover, in addition to the continuous replication in tumor cells, oncolytic viruses can recruit uninfected cells nearby without resulting in chromosomal integration or causing any major disease. ${ }^{24}$ One interesting feature of oncolytic reoviruses, ${ }^{25} \mathrm{HSV}^{26}$ and $\mathrm{VV}^{27}$ is their ability to induce adaptive immunoresponses, which can contribute indirectly to tumor cell death. Similarly, oncolytic Ads ${ }^{28}$ Coxsackie virus (CV) $\mathrm{B} 3,{ }^{29}$ and measles virus (MV) ${ }^{30}$ can induce stress of the endoplasmic reticulum, which attracts immune cells and results in immunologic cell death.

Other studies have demonstrated that viral infections of tumors can contribute to the immunosuppressive milieu by inducing immunostimulatory cytokines and chemokines. ${ }^{31-33}$ Although the production of cytokines and chemokines recruits and activates neutrophils, natural killer cells, macrophages, and $\mathrm{CD} 4^{+}$and $\mathrm{CD} 8^{+} \mathrm{T}$ lymphocytes, contributing to viral clearance, it can also alter immunosuppression and stimulate antitumor responses. ${ }^{34-36}$ Moreover, various 
Table I Examples of preclinical cancer therapy applications for viral vectors

\begin{tabular}{|c|c|c|c|c|}
\hline Cancer type & Target & Delivery & Response & Reference \\
\hline \multirow[t]{7}{*}{ Brain } & SLAM, EGFR & MV & Tumor regression & 125 \\
\hline & sTRAIL & AAV9 CBA and NSE promoters & Slower tumor growth & 64 \\
\hline & $\operatorname{miR} I 24$ & SFV-miRTI24 & Prolonged survival & 100 \\
\hline & IL2, ILI 2 & VV & Antitumor response & $14 \mid$ \\
\hline & shRNA MYCN & Ad & Induction of apoptosis & 162 \\
\hline & Decorin & AAV & Promotion of paclitaxel uptake & 65 \\
\hline & HSVI & HSVI, survivin promoter & Selective tumor targeting & 70,71 \\
\hline \multirow[t]{4}{*}{ Breast } & CEA & MV & Tumor-growth delay & 123 \\
\hline & Neu & AAV5, AAV6 & Long-term survival & 62 \\
\hline & CCNY & Lentivirus & Reduced cell proliferation & 82 \\
\hline & Coxsackie virus & CVA2I & Reduced tumor burden in mice & 152 \\
\hline \multirow[t]{7}{*}{ Colon } & MazF-MazE & Ad & Tumor regression & 49 \\
\hline & HSV2 & HSV2 & Prolonged survival & 69 \\
\hline & $\beta$-gal & SFV RNA & Tumor protection & 90 \\
\hline & GM-CSF & Kunjin VLPs & Tumor regression & 109 \\
\hline & VV & VVGLVhI68 & Prolonged survival & 142 \\
\hline & CDI33 & Ad CDI33-TYML & Antitumor response & 55 \\
\hline & ILI2-PDLI & MV Schwarz & Complete remission & 129 \\
\hline Esophageal & hTERT & Ad5 & Tumor regression & 48 \\
\hline \multirow[t]{4}{*}{ Gastric } & RPL23, p53 & Ad & Prolonged survival & 46 \\
\hline & TRAIL, EI & Ad & Prolonged survival & 50 \\
\hline & iNOS + CEA scF & RV & Tumor-growth inhibition & 73 \\
\hline & RNAi CDHI7 & Lentivirus & Decreased tumorigenicity & 81 \\
\hline Leukemia & shRNA MCM7 & Lentivirus & Antitumor activity & 83 \\
\hline \multirow[t]{11}{*}{ Liver } & IL24 & Ad + PEG, lipid, calcium phosphate & Tumor targeting & 52 \\
\hline & IL24, Bcl3 IAP & AAV & Tumor suppression & 60 \\
\hline & HSV-TK & $\mathrm{AAV}$, albumin promoter & Selective tumor killing & 61 \\
\hline & shRNA miR30 IL2 & HIV & Inhibition of proliferation & 79 \\
\hline & MI & $\mathrm{MI}$ & Oncolytic activity & 101 \\
\hline & IL2 & NDV Anhinga & Cure, tumor protection & 133 \\
\hline & TRAIL & NDV Anhinga & Tumor suppression & 134 \\
\hline & TSCLI & Ad-Wnt-EIA-( $\delta 24 b p)-T S L C I$ & Prolonged survival & 54 \\
\hline & MLV, GALV & RV, MLV, GALV & Suppression of tumor growth & 75 \\
\hline & Wtp53-mi30-shRNA & Lentivirus & Inhibition of cell proliferation & 179 \\
\hline & CDI33 & MV VsV & Prolonged survival & 126 \\
\hline \multirow[t]{8}{*}{ Lung } & Decorin, GM-CSF & Ad & Inhibition of lung metastasis & 56 \\
\hline & VEGF & AAV2 & Prevention of metastasis & 58 \\
\hline & $\operatorname{miR} \mid 45$ & HSVI & Reduced cell proliferation & $\mathrm{II}$ \\
\hline & shRNA livin & HIVI & Reduced tumor proliferation & 80 \\
\hline & EGFP & SFV VLPs & Tumor regression & 91 \\
\hline & EGFP & SFVVA7 & Prolonged survival & 95 \\
\hline & EGFP & NDVD90 & Tumor-selective replication & $|3|$ \\
\hline & Coxsackie virus & CVA2I & Reduced tumor burden in mice & 154 \\
\hline Lymphoma & MV Edmonston & MV Edmonston & Tumor regression & 121 \\
\hline \multirow[t]{6}{*}{ Melanoma } & TRPI & SINV DNA & Tumor protection & 92 \\
\hline & SFVVA7 & SFVVA7 & Tumor regression & 93 \\
\hline & GM-CSF & Kunjin VLPs & Tumor regression & 109 \\
\hline & ILI5, ILI2 & NDV & Tumor-growth suppression & 130 \\
\hline & NDV & NDV73T & Improved survival in patients & 136 \\
\hline & Coxsackie virus & CVA2I & Reduced tumor burden in mice & 150 \\
\hline Myeloma & Coxsackie virus & CVA2I & Reduced tumor burden in mice & $|5|$ \\
\hline \multirow[t]{3}{*}{ Ovarian } & CEA, NIS & MV & Tumor regression & 122 \\
\hline & EI & Ad hTERT & Antitumor response & 44 \\
\hline & TRAIL & $\mathrm{RV}+$ cisplatin & Antitumor response & 73 \\
\hline Osteosarcoma & EGFP & SFV-VA7 & Prolonged survival & 94 \\
\hline
\end{tabular}


Table I (Continued)

\begin{tabular}{|c|c|c|c|c|}
\hline Cancer type & Target & Delivery & Response & Reference \\
\hline \multirow[t]{5}{*}{ Pancreatic } & Matrix protein & VSV VLPs & Tumor regression & 114 \\
\hline & $\mathrm{MUCl}$ & VSV VLPs & Tumor-growth reduction & 115 \\
\hline & IFN $\beta$ & Lentivirus & Prevention of cancer progression & 78 \\
\hline & VV & VVGLVIh68 + paclitaxel & Tumor killing & 145 \\
\hline & ILI2 & SINV & Reduced tumor load & 97 \\
\hline \multirow[t]{7}{*}{ Prostate } & CEA & MV & Tumor-growth delay & 124 \\
\hline & AR siRNA & AAV & Tumor suppression & 63 \\
\hline & NIS & HSV & Tumor eradication & 67 \\
\hline & PSCA & HIVI & Tumor protection & 77 \\
\hline & $\beta$-gal & SFV + liposomes, PEG & Tumor targeting & 99 \\
\hline & SFV-VA7 & SFV-VA7 & Tumor targeting & 103 \\
\hline & Coxsackie virus & CVA2I & Reduced tumor burden in mice & 153 \\
\hline Retinoblastoma & IFN $\beta$ & AAV & Antitumor response & 57 \\
\hline Salivary gland & VV & VVGLVIh68 & Tumor regression & 139 \\
\hline \multirow[t]{2}{*}{ Sarcoma } & HSVI & HSVI + PDI & Therapeutic efficacy & 68 \\
\hline & MGI & Rhabdovirus MGI & Long-lasting cure & 117 \\
\hline \multirow[t]{2}{*}{ Skin } & HSVI & HSVI RH2 & Tumor regression & 66 \\
\hline & VV & VV & Long-term regression in $X_{p}$ model & 146 \\
\hline
\end{tabular}

Abbreviations: AAV, adenoassociated virus; Ad, adenovirus; AR, androgen receptor; $\beta$-gal, $\beta$-galactosidase; CVA2I, Coxsackie virus A2I; GALV, gibbon ape leukemia virus; GM-CSF, granulocyte-macrophage colony stimulating factor; HSV-TK, herpes simplex virus thymidine kinase; HSVI, herpes simplex virus I; hTERT, human telomerase reverse transcriptase; IL2, interleukin 2; iNOS, inducible nitric oxide synthase; MV, measles virus; NDV, Newcastle disease virus; PEG, polyethylene glycol; RV, retrovirus; $\mathrm{scF}_{\mathrm{v}}$, single-chain variable fragment; SFV, Semliki Forest virus; SINV, Sindbis virus; VLPs, virus-like particles; VSV, vesicular stomatitis virus; VV, vaccinia virus; Xp, Xeroderma pigmentosum.

antiviral immunoresponses have been shown to contribute to the anticancer activity of oncolytic vesicular stomatitis virus (VSV), Maraba virus, VV, HSV, and reovirus by inducing IFN1, leading to the secretion of several immunostimulatory cytokines and chemokines, such as tumor necrosis factor (TNF) and TRAIL. ${ }^{37}$ Similarly, expression of proinflammatory genes, such as IL12 or IL18, from oncolytic $\mathrm{HSV}^{38}$ and $\mathrm{Ad}^{39}$ vectors has enhanced tumor-specific immunity. Moreover, coexpression of IL12 and CCL2 from an oncolytic HSV vector accelerates the recruitment of activated macrophages and $\mathrm{T}$ cells without affecting virus replication, albeit providing improved survival rates. ${ }^{40}$

An interesting finding relates to enhanced antitumor activity in the presence of preexisting antiviral immunity. While improved survival has been obtained in immunocompetent tumor models, the same phenomenon is not present in immunosuppressed mice. ${ }^{41}$ In contrast, innate immune cells are capable of rapid clearance of replicating oncolytic HSV particles, which presents a significant limitation of oncolytic virotherapy ${ }^{42}$ Furthermore, it was discovered in a Phase IB clinical trial with the oncolytic HSV1-derived $\gamma_{1} 34$.5-deleted G207 vector that a stronger inflammatory response and IFN-stimulated gene expression were detected in long-term survivors compared to nonresponders. ${ }^{43}$ In summary, four phases contribute to oncolytic virotherapy: direct cellular lysis, cytokine-induced apoptosis, innate immune-cell cytotoxicity, and antigen-specific adaptive T-cell killing.

\section{Examples of therapeutic applications of oncolytic viruses}

A number of oncolytic viruses have been subjected to studies in animal-tumor models (Table 1) and in a few clinical trials (Table 2). Ads represent the most frequently used viral vectors subjected to cancer therapy. For instance, animal models for ovarian, ${ }^{44}$ prostate, ${ }^{45}$ gastric,${ }^{46}$ and brain cancer ${ }^{47}$ have been established. Related to gastric cancer, expression of RPL 23 and $\mathrm{p} 53$ from a bicistronic Ad vector provides significantly better tumor-suppression activity in gastric cancer cells and antitumor responses in MKN45 cells compared to administration of the Ad-p53 vector alone ${ }^{46}$ Furthermore, administration of the bicistronic Ad-RPL23/p53 shows survival benefits in a human gastric tumor model. In another approach, oncolytic Ad expressing luciferase (VRX007Luc) was subjected to intratumoral injections in a Syrian hamster model, which provided similar levels of inhibition of tumor growth, as observed for immunosuppressive and chemotherapeutic agents such as cyclophosphamide. As human telomerase activity is present in more than $85 \%$ of primary cancers, the human telomerase reverse transcriptase (hTERT) promoter has been inserted into an attenuated Ad5 vector, resulting in significant tumor regression in an esophageal tumor model. ${ }^{48}$ Furthermore, introduction of the bacterial MazF-MazE toxin-antitoxin system into an Ad vector has provided dose-dependent killing of KRAS cells and considerable tumor shrinkage in vivo without displaying 
Table 2 Examples of clinical cancer therapy applications for viral vectors

\begin{tabular}{|c|c|c|c|c|}
\hline Cancer type & Target & Delivery & Response & Reference \\
\hline \multirow[t]{3}{*}{ Bladder } & GM-CSF & Ad CG0070 & Good tolerance, antitumor activity & 165 \\
\hline & GM-CSF & Ad CG0070 & Close to approval & 191 \\
\hline & $\mathrm{VV}$ & Dryvax VV & Safe delivery in Phase I & 171 \\
\hline \multirow[t]{6}{*}{ Brain } & ILI2 & HSVI & Phase I design & 178 \\
\hline & HSV + radiation & HSVI G207 & Phase I safety & 179 \\
\hline & HSV & HSVI G207 & Phase IB, antitumor activity & 180 \\
\hline & HSV + radiation & HSVI G207 & Phase I design & 43 \\
\hline & HSVI & HSVI G47 & Fast-track approval & 190 \\
\hline & NDV & NDV Ulster & Long-term survival in patients & 137 \\
\hline \multirow[t]{6}{*}{ Head and neck } & NDV & NDV73T & Improved survival rate in patients & 138 \\
\hline & VV & VV GL-ONCI & Improved survival in patients & 147 \\
\hline & p53 & Ad & Approved drug & 185 \\
\hline & $\mathrm{p} 53$ & Ad EIB55K deletion & Approved drug & 185 \\
\hline & Reolysin + paclitaxel/CPlat & Reovirus & No toxicity in Phase I/II & 176 \\
\hline & Pelareorep & Reovirus & Close to drug approval & 192 \\
\hline \multirow[t]{3}{*}{ Kidney } & ILI2 & SFV + liposomes, PEG & Tumor targeting, clinical safety & 99 \\
\hline & NDV & PV70I & Objective responses in Phase I & 168 \\
\hline & VV & VVJX594 & Phase I evaluation & 170 \\
\hline Liver & VV & VVJX594 & Close to drug approval & 189 \\
\hline \multirow[t]{7}{*}{ Melanoma } & ILI2 & SFV + liposomes, PEG & Tumor targeting, clinical safety & 99 \\
\hline & NDV & NDV73T & Improved survival in patients & 136 \\
\hline & GM-CSF & HSVI & Approved drug & 187 \\
\hline & Reovirus & Reovirus & Safe delivery, Phase II & 175 \\
\hline & $\mathrm{CV}$ & CVA2I & Antitumor activity in Phase I/II & 182 \\
\hline & $\mathrm{CV}$ & CVA2I & Immunoresponse in Phase II & 183 \\
\hline & $\mathrm{CV}+$ pembrolizumab & CVA2I & Response in Phase IB & 184 \\
\hline Pancreatic & Reolysin + paclitaxel/CPlat & Reovirus & Safe delivery, Phase II & 174 \\
\hline \multirow[t]{5}{*}{ Prostate } & Adenovirus & CG7870 & Decreased serum PSA in Phase I & 166 \\
\hline & CD/HSV-TK & Adenovirus & Decreased serum PSA in Phase I & 167 \\
\hline & PSMA & VEE & Neutralizing antibodies in Phase I & 181 \\
\hline & Pelareorep & Reovirus & Repeated delivery in Phase I & 173 \\
\hline & PSA & VV & Immunoresponse in Phase I & 172 \\
\hline
\end{tabular}

Abbreviations: Ad, adenovirus; CD, cytosine deaminase; CPlat, carboplatin; CV, Coxsackie virus; GM-CSF, granulocyte-macrophage colony-stimulating factor; HSV-TK, herpes simplex virus thymidine kinase; NDV, Newcastle disease virus; PEG, polyethylene glycol; PSMA, prostate-specific membrane antigen; PSA, PS antigen; SFV, Semliki Forest virus; VEE, Venezuelan equine encephalitis; VV, vaccinia virus.

any side effects. ${ }^{49}$ Similarly, an oncolytic Ad vector with a tumor-specific promoter expressing the TRAIL and E1A genes has induced apoptosis in gastric cancer cell lines, inhibition of peritoneal metastasis, and prolonged survival in tumor-bearing mice..$^{50}$ In attempts to improve oncolytic Ads, incorporation of polymers, liposomes, and nanoparticles has extended the circulation time and reduced vector-based immunogenicity. ${ }^{51}$ In this context, formulation of oncolytic vectors with polyethylene glycol, lipids, and calcium reduces liver sequestration and systemic toxicity of oncolytic Ads expressing IL24 (PLC-ZD55-IL24) in BALB/c mice..$^{52}$ Intravenous injection demonstrates efficient targeting of Huh7 tumors, with no observed toxicity.

Related to neuroblastoma, multidrug resistance has been a major issue hindering successful chemotherapy. It has triggered the engineering of an oncolytic Ad vector carrying shRNAs against the MYCN oncogene (ZD55-shMYCN), which correlates with the expression of the protein MRP. ${ }^{53}$ ZD55-shRNA-based downregulation of MYCN inhibited tumor-cell proliferation and induced apoptosis in neuroblastoma cells. Furthermore, ZD55-shRNA was capable of resensitizing doxorubicin-resistant cells to doxorubicin and resulted in reduced proliferation, increased apoptosis, and inhibited cell migration, which reduced the in vivo growth rate of neuroblastoma xenografts. In another approach, the dualregulated oncolytic Ad wnt-E1A( $\delta 24 \mathrm{bp})-\mathrm{TSLC} 1$ targeting the Wnt- and Rb-signaling pathways and carrying the TSLC1 tumor suppressor was engineered. ${ }^{54}$ In vivo administration showed efficient inhibition of growth of transplanted tumors of hepatic cancer stem cells and prolonged survival in mice. Oncolytic Ad vectors targeted to the CD133 (prominin 1) cell-surface marker present on cancer stem cells have been developed by Ad-library screening. ${ }^{55}$ The engineered vector with the CD133-targeting motif (AdML-TYML) showed 
selective infection and lysis of CD133+-cultured cells. Nude mice vaccinated with AdML-TYML were protected against challenges with $\mathrm{CD}_{133^{+}}$colorectal carcinoma (CRC). Moreover, strong antitumor responses were observed in mice with established $\mathrm{CD} 133^{+} \mathrm{CRC}$ xenografts after intratumoral injections of AdML-TYML. In another study on CRC, oncolytic Ads expressing decorin (DCN), a regulator of cancer development and progression, and the granulocyte-macrophage colony-stimulating factor (GM-CSF) showed significant inhibition of tumor growth and lung metastasis after intratumoral administration in mice with implanted CT26 xenografts. ${ }^{56}$ Furthermore, multiple protumorigenic pathways were downregulated and antitumor immunoresponses activated.

AAV vectors have also been evaluated in a number of cancer-therapy studies. One issue of concern has been the strong immunogenicity presented by readministration of AAV vectors. ${ }^{18}$ As a special case due to the immunoprivileged nature of the eye, intravitreal injection of AAV expressing IFN $\beta$ has provided a strong antitumor effect in a preclinical retinoblastoma model without any issues of readministration. ${ }^{57}$

Despite immunogenicity issues, AAV2-based expression of VEGF generates prevention of pulmonary metastases in mice with implanted $4 \mathrm{~T} 1$ tumors $^{58}$ In another approach, AAV3 targets hepatoblastoma and hepatocellular carcinoma (HCC) cell lines efficiently by using hepatocyte growth factor receptor (HGFR) as a cellular coreceptor. ${ }^{59}$ Furthermore, AAV vectors have been used in combination therapy of the p53-independent Bcl3-insensitive apoptotic protein and IL24 in HepG2 cells and nude mice in vivo. ${ }^{60}$ In another study on HCC, HSV-TK expression driven by the albumin promoter and human alpha-fetoprotein (AFP) enhancer from AAV showed selective killing of AFP-positive HCC cells, but not nonhepatocyte tumor cells or AFP- or albumin-negative hepatic tumor cells.$^{61}$ In the context of oral administration, AAV5 and AAV6 serotypes expressing a truncated form of the $\mathrm{Neu}$ oncogene have shown significantly improved survival and long-lasting protection in $80 \%$ of mice implanted with Neu-positive TUBO breast tumors. ${ }^{62}$

$\mathrm{AAV}$ vectors have also been applied in gene silencing. In this context, two unique shRNAs induced apoptotic cell death in androgen receptor-positive prostate cancer cells and suppressed tumor growth after intratumoral injection of mice with implanted xenografts from either androgen-responsive or castration-resistant prostate cancer cells. ${ }^{63}$ Furthermore, tail-vein injections provided xenograft elimination within 10 days. Engineering of the ubiquitous chicken beta actin (CBA) and neuron-specific enolase (NSE) promoters into an AAV9 vector was monitored for bioluminescent reporter-gene expression after intravenous administration. ${ }^{64}$ The AAV9 vector carrying the NSE promoter showed 100 -fold lower expression in the liver. The AAV9-CBA vector targeted astrocytes, neurons, and endothelial cells, while the AAV9-NSE vector provided mainly neuron-specific expression. Moreover, both AAV9-CBA and AVV9-NSE expressing sTRAIL generated slower tumor growth and significantly prolonged survival in mice with intracranial xenografts from glioblastoma patients. Recently, DCN expression from AAV vectors was evaluated in vitro and in vivo. ${ }^{65}$ It was demonstrated that transduced neuroblastoma cells expressed DCN and systemic administration of AAV-DCN in nude mice promoted intratumoral uptake of paclitaxel.

HSV-based cancer therapy has been verified in a syngenetic $\mathrm{C} 3 \mathrm{H}$ squamous-cell carcinoma model using the lytic HSV1 RH2 vector. ${ }^{66}$ In addition to therapeutic efficacy observed after intratumoral injection, growth in contralateral tumors was also significantly suppressed. In another application, an oncolytic HSV1 vector containing four copies of miR145 targeting the 3'-end untranslated region (UTR) of the essential HSV ICP27 gene was able to decrease cell proliferation and prevention of colony formation of non-small-cell lung cancer (NSCLC) cells, which further enhanced cancer-cell killing when combined with radiotherapy. ${ }^{11}$ It has also been demonstrated that oncolytic HSV vectors expressing NIS increased antitumor activity by concentration of radioactive iodine in human prostate $\mathrm{LNCaP}$ cells. ${ }^{67}$ Moreover, intratumoral injection of HSV-NIS resulted in efficient tumor eradication in nude mice implanted with LNCaP xenografts, and systemic administration provided prolonged survival. Oncolytic HSV vectors have also been tested in syngenetic mouse-rhabdomyosarcoma models in combination therapy with the cell-death-inhibiting ligand PDL1, which might provide a new approach for treatment of childhood soft-tissue sarcomas. ${ }^{68}$ Moreover, oncolytic HSV2 vectors show significant inhibition of tumor growth and prolonged survival of BALB/c mice with implanted CT26 tumors ${ }^{69}$ Additionally, HSV2 replication contributes to reduced myeloid-derived suppressor cells and regulatory $\mathrm{T}$ cells in the spleen, which also decreases the number of dendritic cells in tumor-draining lymph nodes.

A glioma-specific HSV1 amplicon virus has been engineered to target tumor cells selectively by replacing the HSV1 ICP4 promoter with the tumor-specific survivin promoter. ${ }^{70}$ Furthermore, incorporation of 5 miR124 target sequences into the 3 'UTR of the ICP4 gene provided translational regulation. The SU4124 HSV1 vector demonstrated enhanced expression of survivin and eIF4E in glioma cells 
and increased expression of miR124 in normal mouse and human brain tissue. Moreover, a strong antitumor effect was observed in a panel of glioma cell lines. Additionally, significantly increased antitumor activity was discovered in mice with human U87 glioma tumors after intratumoral injections.

An interesting observation relates to enhanced replication of oncolytic HSV in glioblastoma after short-term nutritional restriction (fasting). ${ }^{71}$ Glioblastoma cell lines from human patients subjected to transient fasting for 24 hours increased late HSV expression and improved viral yields. Transient fasting for 48 hours followed by a 24-hour recovery doubled luciferase activity after intratumoral HSV administration in orthotopic glioblastoma xenografts.

Retroviruses have been subjected to a number of cancertherapy applications, including recombinant bifunctional retrovirus vectors expressing a single-chain variable fragment $\left(\mathrm{scF}_{\mathrm{v}}\right)$ antibody to CEA and the inducible nitric oxide synthase (iNOS) gene. ${ }^{72}$ SCID mice subcutaneously injected with MKN45 cells expressing CEA showed significant inhibition in tumor growth with $70 \%$ reduction in tumor size. The problem of drug resistance has been addressed by demonstrating that retroviruses expressing the TRAIL gene are susceptible to A2780/DDP ovarian cancer cells, which in combination with cisplatin treatment enhanced antitumor activity in nude mice with implanted A2780/DDP xenografts. ${ }^{73}$ In attempts to improve the safety of retrovirus-based therapy for hematological malignancies, $\mathrm{T}$ cells with chimeric antigen receptors have been engineered. ${ }^{74}$ Additionally, deletion of oncogenes and inactivation of oncogenic signaling pathways have been achieved by introduction of Cas9, zinc finger nucleases (ZFNs), or transcription activator-like effector nucleases (TALENs) into retrovirus vectors.

Replicating retrovirus vectors based on murine leukemia virus and gibbon ape leukemia virus (GALV) have proven effective in tumor killing. ${ }^{75}$ Comparison of murine leukemia virus and GALV indicated more rapid replication kinetics for the latter in tumors, and in vivo GALV-based suicide-gene therapy demonstrated efficient suppression of HCC-tumor growth. In another study, it was shown that replication competence of retroviruses can provide a powerful tool for generation of novel tumor-specific retrovirus variants, which can be generated by natural selection. ${ }^{76}$ Moreover, retrovirus vectors are able to integrate stably into the genome of cancer cells, which can contribute to long-lasting therapeutic efficacy, keeping in mind that the integration event is controlled to avoid any unwanted effects, as discussed previously. ${ }^{3}$

Belonging to the family of retroviruses, lentiviruses have also found a number of applications in cancer therapy. In this context, lentivirus vectors expressing PSCA have been targeted to DC-SIGN-expressing $293 \mathrm{~T}$ cells and bone marrow-derived dendritic cells, which provided protection against lethal tumor challenges in the TRAMP-C1 synergic tumor model and reduced tumor growth in animals with preexisting tumors. ${ }^{77}$ In another study, self-inactivated lentivirus vectors expressing human IFN $\beta$ achieved $90 \%$ transduction efficiency in pancreatic tumor cell lines, leading to inhibition of cell proliferation and induction of cell death. ${ }^{78}$ Furthermore, progression of pancreatic cancer was prevented for 15 days in mice after administration of lentivirus human IFN $\beta$.

Lentivirus vectors have also been employed in gene silencing. For instance, delivery of lentivirus vectors carrying Wtp53-pPRIME-mi30-shRNA to AFP-positive liver cells resulted in inhibition of proliferation in Hep3B cells and in mice. ${ }^{79}$ Moreover, lentivirus-based delivery of shRNAs for Livin efficiently induced apoptosis in tumor cells, reduced proliferation of tumors, and contributed to cell-cycle arrest. ${ }^{80}$ Reduced proliferation and increased apoptosis was also observed in MKN28 gastric cancer cells and in vivo after delivery of lentivirus vectors carrying CDH17 RNAi. ${ }^{81}$ Related to breast cancer. lentivirus vectors expressing shRNA were used to knock down cyclin Y (CCNY) expression in MCF7 and MDA-MB231 cells, resulting in substantial decrease in cell proliferation and colony formation and inhibition of cancer-cell growth through activation of Bad and GSK $3 \beta$ and cleavage of poly (ADP-ribose) polymerase (PARP) and caspase 3 in a p53-dependent manner. ${ }^{82}$ Lentivirus vectors have also been applied for targeting MCM7 with shRNAs to suppress the endogenous expression in K562 cells as a novel approach for the treatment of leukemia. ${ }^{83}$

In attempts to enhance lentivirus gene transfer, nanofibrils have been engineered to provide highly versatile and broad delivery profiles and to facilitate lentivirus concentration. ${ }^{84}$ Additionally, a platform for insertional mutagenesis was established for lentiviruses to induce HCC efficiently in various mouse models and for the identification of four previously unknown liver cancer-associated genes. ${ }^{85}$ In another approach, lentivirus vectors were pseudotyped with truncated MV glycoproteins, which provided targeting of lymphocytes and antigen-presenting cells through signaling lymphocyte activation molecule (SLAM) acting as an entry receptor. ${ }^{86}$ Reportergene expression confirmed the targeting, and administration of pseudotyped lenti-MV glycoproteins showed predominant induction of antigen-specific $\mathrm{CD}^{+} \mathrm{T}$ cells and suitability for vaccines eliciting antigen-specific immunoresponses.

Alphaviruses have been subjected to vector engineering, especially for Semliki Forest virus (SFV), ${ }^{87} \mathrm{SINV},{ }^{88}$ and Venezuelan equine encephalitis (VEE) virus. ${ }^{89}$ Applications for cancer therapy have included administration of RNA 
replicons, recombinant alphavirus particles, and layered DNA vectors. For instance, immunization of mice with SFV-LacZ RNA demonstrated tumor regression and provided protection against challenges with tumor cells. ${ }^{90}$ Likewise, SFV EGFP particles subjected to intratumoral injections resulted in tumor regression in immunodeficient mice with human lung carcinoma xenografs. ${ }^{91}$ Additionally, immunization of mice with SINV plasmid DNA carrying the TRP1 gene showed antitumor activity and immunoprotection in mice. ${ }^{92}$

Oncolytic alphaviruses occur naturally and have also been engineered from avirulent SFV strains. High infection rates and lysis of cancer cells were observed for the avirulent SFVA7(74) strain (SFVVA7) and a single intraperitoneal or intravenous injection showed significant tumor regression in SCID mice with established melanomas. ${ }^{93}$ Similarly, improved survival rates were observed after SFV-VA7EGFP administration in nude mice with osteosarcoma ${ }^{94}$ and orthotypic lung-tumor xenografts. ${ }^{95}$ Furthermore, SFVVA7-EGFP particles demonstrated efficient replication and killing of two canine-tumor cell lines, and no adverse events occurred in beagle dogs after intravenous administration of $2 \times 10^{5}$ particles. $^{96}$

Adequate attention has been paid to tumor targeting of alphavirus vectors. In this context, it has been shown that SINV particles possess natural tumor targeting after intraperitoneal administration of mice implanted with tumor xenografts, and subcutaneous SINV-IL12 administration reduced the tumor load to $6.2 \%$ of control mice. ${ }^{97}$ In contrast, studies on SFV particles showed no tumor targeting. ${ }^{98}$ For this reason, liposome-encapsulated SFV particles were engineered to provide tumor targeting of $\beta$-galactosidase after systemic delivery of SFV-LacZ particles in SCID mice. ${ }^{99}$ Moreover, encapsulated SFV-IL12 particles showed good safety profiles in kidney carcinoma and melanoma patients. ${ }^{99}$ Another approach comprises engineering six tandem neuron-specific miR124 sequences between the nsP3 and nsP4 genes in the SFV4 genome, which provided glioma targeting and limited spread in the central nervous system (CNS) in BALB/c mice after intraperitoneal delivery of SFV4-miR124 particles. $^{100}$ Moreover, the naturally occurring oncolytic M1 alphavirus is capable of selective killing of zinc-finger antiviral protein (ZAP)-deficient cancer cells, providing potent oncolytic efficacy and high tumor tropism in vitro and in vivo. ${ }^{101}$ In another study, the safety of M1 was evaluated in nonhuman primates prior to initiation of clinical trials. ${ }^{102}$ Five macaques received three rounds of $10^{9} \mathrm{pfu}$ of $\mathrm{M} 1$ intravenously and were monitored for a number of physiological and biochemical parameters, neutralizing antibodies, and clinical symptoms.
No clinical, biochemical, immunological, or medical imaging indicated any evidence of toxicity, suggesting that M1 can be safely used for intravenous administration in cancer patients.

Recently, SFV-VA7 particles were evaluated in human VCaP, LNCaP, and 22Rv1 prostate cancer cell lines and in the nonmalignant RWPE1 prostate epithelial cell line, as well as in subcutaneous and orthotopic mouse LNCaP xenograft models. ${ }^{103}$ Interestingly, all prostate cancer cell lines, irrespective of their hormone-response status, were efficiently killed by SFVVA7, whereas RWPE1 cells were resistant to SFVVA7, indicating tumor targeting of SFV. This result is in contrast to previous findings of lack of tumor targeting of SFV particles. ${ }^{98}$ In vivo, a single peritoneal dose of SFVVA7 showed eradication of all subcutaneous and orthotopic LNCaP tumors.

Flaviviruses are enveloped ssRNA viruses engineered for recombinant protein expression and cancer therapy. ${ }^{104-108}$ For example, Kunjin virus vectors expressing GM-CSF provided cure in more than $50 \%$ of mice with established subcutaneous CT26 colon carcinomas after intratumoral administration. ${ }^{109}$ Moreover, regression of B16-OVA melanoma tumors was obtained after 5 days, with a cure rate of $67 \%$. Subcutaneous administration of Kunjin GM-CSF particles resulted in tumor regression in CT26 lung metastasis in BALB/c mice.

Rhabdoviruses, such as rabies virus ${ }^{110,111}$ and VSV, ${ }^{112}$ have been engineered as expression vectors applicable for cancer therapy with a special emphasis on oncolytic VSV vectors. ${ }^{113}$ The attractive features of VSV comprise high susceptibility of cancer cells, lack of antiviral responses induced by type I IFN, ease of manipulation, replication in the cytoplasm, and no preexisting immunity in humans. VSV particles show superior oncolytic activity in 13 relevant human pancreatic cell lines in comparison to Ads, Sendai virus, and respiratory syncytial virus, although the response is heterogeneous, with some cell lines being resistant to VSV. ${ }^{114}$ Likewise, strong oncolytic activity was obtained in pancreatic ductal adenocarcinoma cell lines after infection with VSV expressing MUC1, and tumor-growth reduction was achieved in vivo. ${ }^{115}$ Combination therapy with gemcitabine further enhanced therapeutic efficacy. In another study, VSV demonstrated apoptotic activity in pancreatic ductal adenocarcinoma cell lines. ${ }^{116}$ However, resistance to apoptosis was seen in three cell lines with high constitutive expression of IFN-stimulated genes. Oncolytic rhabdovirus MG1 particles have shown a strong ability to kill human and canine sarcoma cell lines, and infected more than $80 \%$ of human sarcoma tissues tested ex vivo. ${ }^{117}$ MG1 treatment of sarcoma-bearing mice showed a significant increase in long-lasting cure and also provided 
protection against subsequent tumor challenges. VSV vectors have also been tested for replication in cancer cells from ascites. ${ }^{118}$ Administration of $10^{8} \mathrm{pfu}$ generated a significant inhibition of ascites formation and prolonged survival in mice. Moreover, metabolic adaptive processes in peritoneal carcinoma, including high glycolytic activity and glutamine metabolism, favored VSV replication.

MVs, similar to rhabdoviruses in possessing an enveloped ssRNA genome, have also been subjected to vector development for cancer therapy. ${ }^{119,120}$ Oncolytic Edmonston B (MV Edm) has been employed in studies in xenograft and syngeneic models. For instance, tumor regression was observed in SCID mice implanted with lymphoma xenografts after intratumoral administration of MV Edm. ${ }^{121}$ MV-based dual therapy with CEA and thyroidal NIS showed a superior outcome in treatment of mice with implanted SKOV3ip.1 ovarian tumor xenografts in comparison to administration of MV CEA or MV NIS individually. ${ }^{122}$ Related to breast cancer, MV-CEA vectors provided significant tumor-growth delay and prolonged survival in an MDA-MB231 mammary-tumor model. ${ }^{123}$ Furthermore, intratumoral MV-CEA administration resulted in delayed tumor growth and extended survival in mice with implanted subcutaneous PC3 prostate tumors. ${ }^{124}$ Tumor targeting of MV vectors was achieved by introduction of CD46 and SLAM into the hemagglutinin protein combined with the display of a single-chain antibody against EGFR. ${ }^{125}$ The retargeted vector showed antitumor activity but no neurotoxicity in MV replication-permissive transgenic mice after systemic administration. Another attempt to target MV vectors involved engineered MV vectors based on the cancer stem-cell marker CD133 (prominin 1). ${ }^{126}$ Selective tumor targeting was obtained by replacing the MV hemagglutinin receptor with a $\mathrm{CD} 133$-specific $\mathrm{scF}_{\mathrm{v}}$. Furthermore, engineered chimera between MV CD133 and VSV showed highly selective elimination of $\mathrm{CD}_{133^{+}}$cells. The VSV-CD133 vector revealed highly potent oncolytic activity in HCC and prolonged survival of mice after intravenous injection. Moreover, VSV CD133 infected a $>10^{4}$-fold larger tumor area in comparison to MV CD133. In another approach, MV vectors based on the MV Schwarz strain encoding a fusion of IL12 and an antibody against PDL1, respectively, resulted in complete remission in $90 \%$ of tested mice with established tumors. ${ }^{127}$

NDV is another ssRNA virus, and belongs to the paramyxoviruses. The oncolytic properties of NDV vectors have made them attractive for cancer therapy, which has been confirmed in several animal-tumor models. ${ }^{128,129}$ Comparison of NDV-based expression of IL12 and IL15 indicated lower toxicity of IL15 in mice with implanted melanoma tumors, and intratumoral administration showed efficient suppression of tumor growth for both ND IL12 and NDV IL 15. ${ }^{130}$ Although not statistically significant, the survival rate was $12.5 \%$ higher for NDV IL15. The reverse genetically engineered NDVD90 strain expressing EGFP showed tumorselective replication, induction of apoptosis in A549 lung cancer cells, and suppression of tumor growth in vivo. ${ }^{131}$ Furthermore, a highly virulent NDV strain adapted for replication in HeLa cells promoted upregulation of TRAIL and caspase activation through induction of apoptosis. ${ }^{132}$ Interestingly, the NDV Anhinga strain carrying the IL2 gene showed strong inhibition of $\mathrm{HCC}$ growth, providing both complete cure and protection against tumor challenges 60 days after immunizations. ${ }^{133}$ In another study, administration of the recombinant NDV Anhinga strain expressing TRAIL resulted in efficient HCC suppression without showing any significant toxicity in normal tissue. ${ }^{134}$ Related to NDV epidemics in poultry, an oncolytic vector based in the NDV-73T strain with a modified fusion-protein cleavage site and a 198-nucleotide insertion in the HNL intergenic region was engineered, which showed significantly reduced viral gene expression and replication in avian cells, but not in mammalian cells. ${ }^{135}$ Moreover, intratumoral and intravenous administration generated selective replication and killing of tumor cells.

A number of Phase I-III clinical trials applying NDV vectors have been conducted for melanomas, ${ }^{136}$ glioblastomas, ${ }^{137}$ and head and neck cancer, ${ }^{138}$ with some encouraging results. For instance, treatment with mesogenic NDV73T resulted in more than $60 \% 10$-year survival in comparison to $6 \%-33 \%$ in the control group. ${ }^{136}$ Moreover, the lentogenic NDV Ulster strain demonstrated long-term survival of one glioblastoma patient in comparison to none in the control group. ${ }^{137}$ Similarly, the 5-year survival rate was $51 \%$ in a Phase II study on head and neck cancer with the NDV-73T strain. ${ }^{138}$

Poxviruses carry a large dsDNA genome with a good packaging capacity of foreign DNA and tumor-selective properties providing cellular destruction by viral replication. ${ }^{139}$ Introduction of deletions in the $T K$ and $V G F$ genes allow replication in tumor cells, while normal cells are not affected. ${ }^{140}$ Moreover, the modified poxvirus vector enhances immunorecognition of tumors. Furthermore, expression of IL2 or IL12 from a VV vector generates antitumor activity in mice with implanted C6 gliomas. ${ }^{141}$ Oncolytic VVs, such as GLV1h68, have lysed human COLO205, HCT15, HCT116, HT29, and SW20 CRC lines efficiently, and significantly inhibited tumor growth and prolonged survival in athymic mice with established colorectal xenografts after a 
single GLV-1h68 intravenous injection. ${ }^{142}$ Likewise, human salivary-gland carcinoma cells were susceptible to GLV1h68, and a single intravenous administration resulted in significant tumor regression. ${ }^{143}$ Genetic modifications made to the VV GLV1h151 vector enhanced cancer specificity, resulting in efficient infection, replication, and killing of several cancerbased (breast, lung, pancreatic, and colorectal) cell lines. ${ }^{144}$ Intravenous injection of VV GLV1h151 confirmed replication in tumors in vivo. The oncolytic GLV1h68 was further evaluated in combination with chemotherapy applying nabpaclitaxel and gemcitabine, which provided enhanced tumorcell killing in two of four human pancreatic adenocarcinoma cell lines. ${ }^{145}$ The feasibility of chemovirotherapy seemed to be related to efficient viral replication, as the nonresponsive tumor-cell lines showed only low levels of viral replication.

VV vectors have also been applied in tumor-bearing Xeroderma pigmentosum (XP) patients excluded from conventional DNA-damaging therapy. ${ }^{146} \mathrm{VV}$ vectors demonstrated ten- to 100-fold higher cytotoxicity in tumor-derived cells from XP patients compared to normal control cells, and systemic administration showed long-term tumor regression in XP animal models. The oncolytic GL-ONC1 VV vector was administered intravenously in combination with chemoradiotherapy in patients with primary nonmetastatic head and neck cancers. ${ }^{147}$ The follow-up of patients indicated 1-year progression-free survival and overall survival of $74.4 \%$ and $84.6 \%$, respectively, which demonstrated the safety and feasibility of GL-ONC1 delivery.

CVs belong to the family of Picornaviridae, with an ssRNA of positive polarity and an nonenveloped structure. ${ }^{148}$ They are known pathogens, and present the leading causes of aseptic meningitis. However, CVA21 has shown promise as an oncolytic vector and demonstrated potential in preclinical cancer models. ${ }^{149}$ In this context, decreased tumor burden has been obtained in tumor models for melanoma, ${ }^{150}$ multiple myeloma, ${ }^{151}$ breast, ${ }^{152}$ prostate,${ }^{153}$ and lung ${ }^{154}$ cancers. More specifically, multiple-myeloma cell lines have shown high susceptibility to CVA21, resulting in lytic infection. Moreover, when biopsies from patient bone marrow were challenged with CVA21, specific removal of $98.7 \%$ of CD138 ${ }^{+}$plasma cells was obtained with no decrease in the functionality of progenitor cells. For this reason, CVA21 administration might provide an efficient approach for multiple-myeloma treatment prior to transplantation of autologous stem cells. In another approach, a large-scale two-step screening procedure for 28 enteroviral strains was conducted, which identified that CVB3 presented oncolytic activity against nine human NSCLC cell lines. CVB3 induced apoptosis and activated kinase-signaling pathways. Intratumoral CVB3 administration generated substantial tumor regression in mice with established NSCLC tumors. Interestingly, injection of CVB3 into tumors located on the right flank demonstrated replication-competent CVB3 and significant regression in xenografts on the left flank. It was also discovered that intratumoral administration of CVB3 recruited natural killer cells and granulocytes, thereby providing immunostimulatory activity.

\section{Optimization and selection of oncolytic viruses}

A number of efforts have been made to optimize oncolytic viral vectors. In this context, a CD133-targeting motif (TYML) was introduced into an Ad vector, and provided selective infection and killing of CRC cells and protection against $\mathrm{CRC}$ challenges. ${ }^{55}$ Similarly, MV vectors with CD133-specific $\mathrm{scF}_{\mathrm{v}}$ showed potent oncolytic activity and prolonged survival in tumor-bearing mice. ${ }^{126}$ Moreover, dual expression of GM-CSF and decorin (regulator of cancer development and progression) from Ad vectors led to significant inhibition of tumor growth and lung metastasis in vivo. ${ }^{56}$ Also, decorin delivery by AAV promoted intratumoral paclitaxel uptake. ${ }^{65}$

Another approach consists of gene silencing, of which examples for antitumor activity have been demonstrated for shRNAs for $\mathrm{AAV}^{63}$ and miRNAs for HSV1 ${ }^{70}$ and lentiviruses. ${ }^{79}$ Furthermore, introduction of six tandem neuronspecific miR124 sequences into the SFV vector has resulted in glioma targeting and only limited spread in the CNS. ${ }^{100}$ Promoter engineering has also allowed enhanced expression targeting, as demonstrated by neuron-specific delivery and 100-fold lower presence in the liver by applying the NSE promoter in AAV9 vectors. ${ }^{64}$ Selective targeting of tumors has also been achieved by replacing the HSV1 ICP4 promoter with the tumor-specific survivin promoter. ${ }^{70}$ Moreover, retroviruses have been subjected to chimeric antigen-receptor engineering to provide safe treatment of hematological malignancies. ${ }^{74}$

Selection of oncolytic virus strains has also been of great importance. In this context, the naturally occurring M1 alphavirus has shown potent oncolytic activity and high tumor tropism, ${ }^{101}$ which further demonstrated no evidence of toxicity in macaques and indicated safe intravenous administration in cancer patients. ${ }^{102}$ Similarly, plenty of attention has been paid to reverse engineering of NDV strains, such as NDVD90, which showed tumor-selective replication and decrease in tumor growth. ${ }^{131}$ Similarly, the NDV Anhinga strain has been subjected to preclinical studies for HCC treatment. ${ }^{133,134}$ 
Moreover, engineering of the NDV73T strain resulted in reduced viral replication in avian but not mammalian cells. ${ }^{135}$ Oncolytic poxvirus strains, such as VV GLV1h68, have also been selected, which have shown antitumor activity for both $\mathrm{CRC}^{142}$ and salivary-gland carcinoma. ${ }^{143}$ Genetic modifications have enhanced cancer specificity for the VV GLV1h151 vector, ${ }^{144}$ and when combined with paclitaxel and gemcitabine further increased tumor-cell death. ${ }^{145}$

\section{Effects on tumor vasculature}

Oncolytic viruses have also shown selective targeting of tumor vasculature. For instance, VSV caused thrombosis in tumor vessels by selective infection of endothelial cells in the tumor microenvironment. ${ }^{155}$ Moreover, HSV and VV are capable of selectively provoking damage to the tumor endothelium. ${ }^{156,157}$ Oncolytic VV vectors have been engineered to express antiangiogenic factors, such as VEGF inhibitors, which leads to suppression of VEGF levels and decrease in perfusion within tumors. ${ }^{158,159}$ Furthermore, oncolytic VV-based targeting of VEGF provided a synergistic antitumor effect with VEGFR tyrosine-kinase inhibitors. ${ }^{160}$ This synergism may be caused by off-target inhibition of cellular antiviral defense proteins, such as dsRNA-dependent protein kinases. ${ }^{161,162}$ In the context of the aggressive anaplastic thyroid carcinoma (ATC), oncolytic Ad d1922-947 induced cell death in vitro and tumor regression in animal models. ${ }^{163}$ It was also demonstrated that Ad d1922-947 decreased IL8/CXCL8 and MCP-1/CCL2 expression in the 8505-c and BHT101-5 ATC cell lines and reduced IL8 impaired ATC-induced angiogenesis in vivo. Overall, the oncolytic Ad reshaped the protumorigenic ATC microenvironment by modulation of intrinsic cancer-cell factors and immunoresponses.

\section{Clinical trials using oncolytic viruses}

The progress made in cancer therapy with oncolytic viruses in preclinical studies has further encouraged the transition into clinical trials. A large number of studies employing, eg, Ad, alphavirus, HSV, reovirus, NDV, MV, and CV vectors have been conducted or are in progress. ${ }^{164}$ In this context, the safety, pharmacokinetics, and anticancer activity of an intravesical oncolytic Ad (CG0070) was evaluated in a Phase I trial in 35 patients with non-muscle-invasive bladder cancer. ${ }^{165}$ Patients received intravesically either a single or multiple doses of $10^{12}, 3 \times 10^{12}, 1 \times 10,{ }^{13}$ and $3 \times 10^{13}$ viral particles, respectively, three times every 28 days or six times weekly. Due to grade 1-2 bladder toxicity, a maximum tolerated dose (MTD) was not reached, although the safety profile was tolerable and anti-bladder cancer activity observed. Ads have also been subjected to several clinical trials in prostate cancer patients, including a replication-selective PSA-targeted oncolytic vector ${ }^{166}$ and a replication-competent vector providing double-suicide-gene therapy, ${ }^{167}$ which resulted in decreased serum levels of PSA.

NDV has also been subjected to several Phase I-III clinical trials. ${ }^{136-138}$ A 10-year observation of 83 postsurgical patients with stage II malignant melanoma treated with NDV demonstrated no presence of disease in $60 \%$, which is remarkable in comparison to similar studies showing only 5\%-33\% survival. Moreover, exceptional survival was seen in 21 patients with head and neck cancer and six individuals with cerebral metastases. NDV has also been applied in the treatment of 23 patients with a vaccine consisting of NDV-infected patient-isolated glioblastoma cells followed by $\gamma$-irradiation. ${ }^{137}$ The NDV therapy caused no severe side effects and showed longer median progression-free survival (40 weeks for NDV treatment and 26 weeks for controls) and median overall survival (100 weeks for vaccinated and 49 weeks for controls). Furthermore, 91\% of the NDV-treated patients survived for 1 year compared to $45 \%$ for controls, and long-term survival was $4 \%$ and 0 for vaccinated and control patients, respectively. In another study, 20 patients with head and neck squamous-cell carcinoma preconditioned with IL2 were vaccinated with NDV-infected autologous tumor cells, which increased systemic antitumor activity. ${ }^{138}$ The replication-competent NDV PV701 strain was evaluated in a Phase I trial in renal cancer patients. ${ }^{168}$ An MTD of $1.2 \times 10^{10} \mathrm{pfu} / \mathrm{m}^{2}$ was established, with only flu-like adverse events. Moreover, objective responses were observed and progression-free survival ranged from 4 to 31 months.

Oncolytic VV vectors, such as GL-ONC1, were subjected to a Phase I clinical trial in combination with radio- and chemotherapy in patients with primary nonmetastatic head and neck cancer. ${ }^{147}$ Adverse reactions, such as fever, fatigue, rash, nausea, and vomiting, were observed among the 19 patients recruited. The MTD was not reached, but patient follow-up demonstrated 1-year (2-year) progression-free survival and overall survival of $74.4 \%$ (64.1\%) and $84.6 \%$ $(69.2 \%)$, respectively, indicating safe application of VV in cancer patients undergoing radio- and chemotherapy. In another study, the oncolytic VV vector JX594 was evaluated in patients with refractory primary or metastatic liver cancer. ${ }^{169}$ JX594 provided direct oncolysis and overexpression of GM-CSF, thereby stimulating the shutdown of tumor vasculature and antitumor immunoresponses. Fourteen patients with refractory primary or metastatic liver tumors received one of four doses $\left(10^{8}, 3 \times 10^{8}, 10^{9}\right.$, or $\left.3 \times 10^{9} \mathrm{pfu}\right)$ every 
3 weeks. All patients showed grade I-III flu-like symptoms, four patients presented dose-related thrombocytopenia, and grade III hyperbilirubinemia dose limitations at the highest dose defined the MTD as $10^{9} \mathrm{pfu}$. Tumor responses were observed in injected and noninjected tumors. Three patients showed partial responses, six presented stable disease, and one demonstrated progressive disease. VVJX594 has been further evaluated in patients with metastatic refractory renalcell carcinoma. ${ }^{170}$ In another approach, a dose-escalating study with intravesical Dryvax VV was conducted in bladder cancer patients. ${ }^{171}$ Viral infection was detected in tumor and normal urothelial cells. The study indicated that VV was safely delivered into the bladder. VV vectors have also been applied for vaccination of patients with locally recurrent or progressive prostate cancer. ${ }^{172}$ Expression of PSA from a VV vector revealed no dose-limiting toxicity, and intraprostatic administration was safe and elicited significant immunoresponses in the Phase I trial.

Reoviruses have also been subjected to clinical trials. ${ }^{173,174}$ In this context, an oncolytic reovirus (pelareorep) was combined with carboplatin and paclitaxel for the treatment of metastatic pancreatic adenocarcinoma. ${ }^{174}$ In the randomized Phase II trial, paclitaxel-carboplatin + pelareorep was compared to paclitaxel-carboplatin, which resulted in no difference in progression-free survival. The presence of pelareorep generated higher levels of 14 proinflammatory plasma cytokines/chemokines. However, although pelareorep delivery was demonstrated to be safe, it did not improve progression-free survival of paclitaxel-carboplatin treatment, but combination with chemotherapy may improve targeting immunosuppressive mediators and enhance oncolytic virotherapy. In another approach, a Phase II study with replication-competent reovirus was conducted in 21 metastatic melanoma patients. ${ }^{175}$ Patients treated with $3 \times 10^{10}$ tissue culture infectious dose $(\mathrm{TCID})_{50}$ showed good safety profiles, and productive reovirus replication was observed in biopsies. Furthermore, a Phase I/II dose-escalating combination-therapy study with carboplatin-paclitaxel and an oncolytic reovirus in head and neck cancer patients showed no dose-limiting toxicity, with one patient (3.8\%) having a complete response, six patients (23.1\%) partial responses, and two patients (7.6\%) major clinical responses. ${ }^{176}$ Moreover, reoviruses have been subjected to a Phase I study in prostate cancer patients, and demonstrated a good safety profile after repeated intravenous administration and reovirus targeting of metastatic tumors. ${ }^{173}$

The second-generation oncolytic HSV vector M032, which selectively replicates in tumor cells, has been employed for overexpression of IL12 to increase the antitumor effect and provide an antiangiogenic effect to target new-tumor blood-vessel formation. ${ }^{177}$ Demonstration in preclinical models has paved the way for initiating a Phase I clinical trial in patients with recurrent progressive glioblastoma multiforme. Furthermore, safety of the HSVG207 vector has been confirmed in preclinical studies in owl monkeys (genus Aotus) $)^{178}$ and in adult Phase I trials in progressive and recurrent brain tumors. ${ }^{179,180}$ Based on these findings, the design of a Phase I clinical trial to evaluate HSVG207 monotherapy or in combination with radiotherapy has been designed for children with progressive and recurrent malignant supratentorial brain tumors. ${ }^{43}$

Regarding alphaviruses, a Phase I trial has been conducted in patients with metastatic castration-resistant prostate cancer applying VEE particles expressing prostate-specific membrane antigen (PSMA). ${ }^{181}$ In the dose-escalating study, patients received five doses of $0.9 \times 10^{7}$ or $0.36 \times 10^{8} \mathrm{IU}$ of VEE PSMA particles at weeks $1,4,7,10$, and 18 , followed by another round of administration of the higher dose in six patients. No toxicities were observed in any patient, and VEE PSMA was well tolerated. However, no PSMA-specific cellular immunoresponse was observed, although a PSMAspecific signal was registered by enzyme-linked immunosorbent assay. Although neither clinical benefit nor robust immunosignaling was detected, neutralizing antibodies were produced, which indicated that there is a need for dose optimization. In another Phase I trial, replication-deficient SFV IL12 particles were encapsulated in liposomes and subjected to intravenous administration in terminally ill melanoma and kidney carcinoma patients. ${ }^{99}$ No liposome- or virus-related toxicity was observed in any patient. IL12 plasma levels showed a transient five- to tenfold increase, indicating potential immunostimulatory activity. Furthermore, the encapsulation procedure protected the virus from being recognized by the host immune system, allowing repeated administration of SFV IL12 particles.

In the context of CVs, the CVA21 strain has been demonstrated to target ICAM1, which is upregulated in melanoma, NSCLC, and bladder and prostate cancers. ${ }^{182}$ In a Phase I/ II trial, patients received multiple intravenous doses of the bioselected formulation Cavatak of CVA21, which were well tolerated. ${ }^{182}$ Prolonged presence of CVA21 RNA in the serum of some patients suggested that viral replication occurred in tumors. Biopsies from melanoma patients confirmed tumor targeting of CVA21. Moreover, CVA21 seemed to provide increased antitumor activity, which might be further enhanced by combination with immunocheckpoint blockade. Additionally, a Phase II clinical trial in advanced-melanoma 
patients was conducted with CVA21, showing induced immune-cell infiltration in the tumor microenvironment. ${ }^{183}$ Similarly, a Phase IB combination-therapy study with CVA21 and systemic pembrolizumab in 20 advanced-melanoma patients demonstrated a best overall response rate of $60 \%$ and stable disease in $27 \%$ of the patients. ${ }^{184}$ Treatment tolerability was good, with no dose-limiting toxicity and no grade 3 or higher treatment-related adverse events.

\section{Conclusion}

In summary, oncolytic viruses, based on engineered vectors or naturally occurring strains, have proven efficient in various preclinical tumor models providing suppression of tumor growth, tumor regression, and in certain cases complete eradication of existing tumors (Table 1). Immunization has also resulted in protection against tumor challenges. The variety of oncolytic viruses (Ad, AAV, HSV, retrovirus, lentivirus, alphavirus, flavivirus, rhabdovirus, MV, NDV, $\mathrm{CV}$, and poxvirus) allows flexibility related to packaging capacity, host range tropism, and mode of expression (duration, chromosomal integration). It can be concluded that no single oncolytic viral vector is universally superior, and for this reason the decision on which vector to use is to a large extent dictated by specific applications and familiarity with each vector system.

Most encouragingly, clinical trials have been conducted or are in progress for most oncolytic vector systems, and have confirmed safe administration in humans (Table 2). Moreover, therapeutic efficacy has also been achieved. Already some time ago, the first drugs based on oncolytic Ads expressing the $p 53$ gene (Gendicine) ${ }^{185}$ and the Ad H101 vector with an $E 1 B 55 K$ deletion $^{186}$ were approved in China. Recently, the second-generation oncolytic HSV1 GM-CSF vector was approved for the treatment of melanoma in the US and Europe. ${ }^{187,188}$ A number of other drugs based on oncolytic viruses, such as the oncolytic VV JX594 (pexastimogene devacirepvec) for HCC treatment, ${ }^{189}$ Ad CG0070 expressing GM-CSF for bladder cancer, ${ }^{190}$ and pelareorep (Reolysin) based on a wild-type variant of reovirus for head and neck cancer ${ }^{191}$ will most likely be approved in the near future. Additionally, the third-generation oncolytic HSV1 vector $\mathrm{G} 47 \delta$, subjected to a Phase II glioblastoma trial, should receive priority reviewing and fast-track drug approval. ${ }^{192}$ Overall, the drug approvals obtained and the ongoing oncolytic virus development bode well for finding safer and more efficacious cancer drugs in the future.

\section{Disclosure}

The author reports no conflicts of interest in this work.

\section{References}

1. Lundstrom K, Boulikas T. Viral and non-viral vectors in gene therapy: technology development and clinical trials. Technol Cancer Res Treat. 2003;2:471-486.

2. Raper SE, Chirmule N, Lee FS, et al. Fatal systemic inflammatory response syndrome in a ornithine transcarbamylase deficient patient following adenoviral gene transfer. Mol Genet Metab. 2003;80:148-158.

3. McCormack MP, Rabbitts TH. Activation of the T-cell oncogene LMO2 after gene therapy for X-linked severe combined immunodeficiency. N Engl J Med. 2004;350:913-922.

4. Hacein-Bey-Abina S, Garrigue A, Wang GP, et al. Insertional oncogenesis in 4 patients after retrovirus-mediated gene therapy of SCID-X1. J Clin Invest. 2008;118:3132-3142.

5. Tseng JC, Daniels G, Meruelo D. Controlled propagation of replication-competent Sindbis viral vector using suicide gene strategy. Gene Ther. 2009;16:291-296.

6. Lundstrom K. Latest trends in cancer therapy applying viral vectors. Future Virol. 2017;12:667-684.

7. Lin Y, Zhang H, Liang J, et al. Identification and characterization of alphavirus M1 as a selective oncolytic virus targeting ZAP-defective human cancers. Proc Natl Acad Sci U S A. 2014;111:E4504-E4512.

8. Lin E, Nemunaitis J. Oncolytic viral therapies. Cancer Gene Ther. 2004;11:643-664.

9. Kaufman, HL, Kohlhapp FJ, Zloza A. Oncolytic viruses: a new class of immunotherapy drugs. Nat Rev Drug Discov. 2015;14:642-662.

10. Young BA, Spencer JF, Ying B, Tollefson AE, Toth K, Wold WS The role of cyclophosphamide in enhancing antitumor efficacy of an adenovirus oncolytic vector in subcutaneous Syrian hamster tumors. Cancer Gene Ther. 2013;20:521-530.

11. Li JM, Kao KC, Li LF, et al. MicroRNA-145 regulates oncolytic herpes simplex virus-1 for selective killing of human non-small lung cancer cells. Virol J. 2013;10:241.

12. Murphy AM, Besmer DM, Moerdyk-Schauwecker M, et al. Vesicular stomatitis virus as an oncolytic agent against pancreatic ductal adenocarcinoma. J Virol. 2012;86:3073-3087.

13. Zhao L, Liu H. Newcastle disease virus: a promising agent for tumor immunotherapy. Clin Exp Pharmacol Physiol. 2012;39:725-730.

14. Ehrig K, Kilinc MO, Chen NG, et al. Growth inhibition of different human colorectal cancer xenografts after a single intravenous injection of oncolytic vaccinia virus GLV-1h68. J Transl Med. 2013; 11:79.

15. Lundstrom K. New era in gene therapy. In: M. Singh, M. Salnikova, editors. Novel Approaches and Strategies for Biologics, Vaccines and Cancer Therapies. London: Academic Press; 2015:13-37.

16. Lundstrom K. Oncolytic alphaviruses in cancer immunotherapy. Vaccines 2017;5:9.

17. Li D, Xu D, Wang Z, et al. Immunogenicity evaluation of modified adenovirus vaccines expressing porcine circovirus type 2 capsid protein in pigs. Viral Immunol. 2017;30:111-119.

18. Grieger JC, Samulski RJ. Packaging capacity of adeno-associated virus serotypes: impact of larger genomes on infectivity and post-entry steps. J Virol. 2005;79:9933-9944.

19. Fountzilas C, Patel S, Mahalingam D. Review: oncolytic virotherapy, updates and future directions. 2017. Available from: http://www. impactjournals.com/oncotarget/index.php?journal=oncotarget\& page $=$ article $\&$ op $=$ view $\&$ path []$=18309 \&$ path []$=58706$. Accessed November 23, 2017.

20. Alain T, Kim TS, Lun X, et al. Proteolytic disassembly is a critical determinant for reovirus oncolysis. Mol Ther. 2007;15:1512-1521.

21. Marcato P, Shmulevitz M, Pan D, Stoltz D, Lee PW. Ras transformation mediates reovirus oncolysis by enhancing virus uncoating, particle infectivity, and apoptosis-dependent release. Mol Ther. 2007; 15:1522-1530.

22. Strong JE, Coffey MC, Tang D, Sabinin P, Lee PW. The molecular basis of viral oncolysis: usurpation of the Ras signaling pathway by reovirus. EMBO J. 1998;17:3351-3362. 
23. Jamieson AT, Gentry GA, Subak-Sharpe JH. Induction of both thymidine and deoxycytidine kinase activity by herpes viruses. J Gen Virol. 1974;24:465-480.

24. Verheije MH, Rottier PJ. Retargeting of viruses to generate oncolytic agents. Adv Virol. 2012;2012:798526.

25. Prestwich RJ, Errington F, Ilett EJ, et al. Tumor infection by oncolytic reovirus primes adaptive antitumor immunity. Clin Cancer Res. 2008;14:7358-7366.

26. Toda M, Rabkin SD, Kojima H, Martuza RL. Herpes simplex virus as an in situ cancer vaccine for the induction of specific anti-tumor immunity. Hum Gene Ther. 1999;10:385-393.

27. Thorne $\mathrm{SH}$, Contag $\mathrm{CH}$. Integrating the biological characteristics of oncolytic viruses and immune cells can optimize therapeutic benefits of cell-based delivery. Gene Ther. 2008;15:753-758.

28. Diaconu I, Cerullo V, Hirvinen ML, et al. Immune response is an important aspect of the antitumor effect produced by a CD40Lencoding oncolytic adenovirus. Cancer Res. 2012;72:2327-2338.

29. Miyamoto S, Inoue H, Nakamura T, et al. Coxsackievirus B3 is an oncolytic virus with immunostimulatory properties that is active against lung adenocarcinoma. Cancer Res. 2012;72:2609-2621.

30. Donnelly OG, Errington-Mais F, Steele L, et al. Measles virus causes immunogenic cell death in human melanoma. Gene Ther. 2013;20: $7-15$.

31. Cassady KA, Haworth KB, Jackson J, Markert JM, Cripe TP. To infection and beyond: the multi-prolonged anti-cancer mechanisms of oncolytic viruses. Viruses. 2016;8:43.

32. Chiocca EA. The host response to cancer virotherapy. Curr Opin Mol Ther. 2008; 10:38-45.

33. Huang JH, Zhang SN, Choi KJ, et al. Therapeutic and tumor-specific immunity induced by combination of dendritic cells and oncolytic adenovirus expressing IL-12 and 4-1BBL. Mol Ther. 2010;18:264-274.

34. Melchjorsen J, Sørensen LN, Paludan SR. Expression and function of chemokines during viral infections: from molecular mechanisms to in vivo function. J Leukoc Biol. 2003;74:331-343.

35. Wickham S, Lu B, Ash J, Carr DJ. Chemokine receptor deficiency is associated with increased chemokine expression in the peripheral and central nervous systems and increased resistance to herpetic encephalitis. J Neuroimmunol. 2005;162:51-59.

36. Aghi M, Chou TC, Suling K, Breakefield XO, Chiocca EA. Multimodal cancer treatment mediated by a replicating oncolytic virus that delivers the oxazaphosphorine/rat cytochrome P450 2B1 and ganciclovir/ herpes simplex virus thymidine kinase gene therapies. Cancer Res. 1999;59:3861-3865.

37. Beug ST, Tang VA, LaCasse EC, et al. Smac mimetics and innate immune stimuli synergize to promote tumor death. Nat Biotechnol. 2014;32:182-190.

38. Wong RJ, Patel SG, Kim S, et al. Cytokine gene transfer enhances herpes oncolytic therapy in murine squamous cell carcinoma. Hum Gene Ther. 2001;12:253-265.

39. Choi IK, Lee JS, Zhang SN, et al. Oncolytic adenovirus co-expressing IL-12 and IL-18 improves tumor-specific immunity via differentiation of T cells expressing IL-12R $\beta 2$ or IL-18R $\alpha$. Gene Ther. 2011;18: 898-909.

40. Parker JN, Meleth S, Hughes KB, Gillespie GY, Whitley RJ, Markert JM. Enhanced inhibition of syngeneic murine tumors by combinatorial therapy with genetically engineered HSV-1 expressing CCL2 and IL-12. Cancer Gene Ther. 2005;12:359-368.

41. Miller CG, Fraser NW. Requirement of an integrated immune response for successful neuroattenuated HSV-1 therapy in an intracranial metastatic melanoma model. Mol Ther. 2003;7:741-747.

42. Chiocca EA. The host response to cancer virotherapy. Curr Opin Mol Ther. 2008;10:38-45.

43. Waters AM, Johnston JM, Reddy AT, et al. Rationale and design of a phase 1 clinical trial to evaluate HSV G207 alone or with a single radiation dose in children with progressive or recurrent malignant supratentorial brain tumors. Hum Gene Ther Clin Dev. 2017;28: $7-16$.
44. Matthews KS, Alvarez RD, Curiel DT. Advancements in adenoviralbased virotherapy for ovarian cancer. Adv Drug Deliv Rev. 2009;61: 836-841.

45. Ekblad M, Halden G. Adenovirus-based therapy for prostate cancer. Curr Opin Mol Ther. 2009;12:421-431.

46. Zhang Y, Zhang BC, Zhang AR, et al. Co-transduction of ribosomal protein L23 enhances the therapeutic efficacy of adenoviral-mediated p53 gene transfer in human gastric cancer. Oncol Rep. 2013;30:1989-1995.

47. Fu YJ, Du J, Yang RJ, Yin LT, Liang AH. Potential adenovirus-mediated gene therapy of glioma cancer. Biotechnol Lett. 2010;32:11-18.

48. Fujiwara T. A novel molecular therapy using bioengineered adenovirus for human gastrointestinal cancer. Acta Med Okoyama. 2011;65:151-162.

49. Shapira S, Shapira A, Kazanov D, Hevroni G, Kraus S, Arber N. Selective eradication of cancer cells by delivery of adenovirus-based toxins. Oncotarget. 2017;8:38581-38591.

50. Zhou W, Dai S, Zhu H, et al. Telomerase-specific oncolytic adenovirus expressing TRAIL suppresses peritoneal dissemination of gastric cancer. Gene Ther. 2017;24:199-207.

51. Choi JW, Lee JS, Kim SW. Evolution of oncolytic adenoviruses for cancer treatment. Adv Drug Deliv Rev. 2012;64:720-729.

52. Chen J, Gao P, Yuan S, et al. Oncolytic adenovirus complexes coated with lipids and calcium phosphate for cancer therapy. ACS Nano. 2016;10:11548-11560.

53. Li Y, Zhuo B, Yin Y, et al. Anti-cancer effect of oncolytic adenovirusarmed shRNA targeting MYCN gene on doxorubicin-resistant neuroblastoma cells. Biochem Biophys Res Commun. 2017;491:134-139.

54. Zhang J, Lai W, Li Q, et al. A novel oncolytic adenovirus targeting Wnt signaling effectively inhibits cancer-stem like cell growth via metastasis, apoptosis and autophagy in HCC models. Biochem Biophys Res Commun. 2017;491:469-477.

55. Sato-Dahlman M, Miura Y, Huang JL, et al. CD133-targeted oncolytic adenovirus demonstrates anti-tumor effect in colorectal cancer. Oncotarget. 2017;8:76044-76056.

56. Liu Z, Yang Y, Zhang X, et al. An oncolytic adenovirus encoding decorin and GM-CSF inhibits tumor growth in a colorectal tumor model by targeting pro-tumorigenic signals and via immune-activation. Hum Gene Ther. 2017;28:667-680.

57. Shih CS, Laurie N, Holzmacher J, et al. AAV-mediated local delivery of interferon- $\beta$ for the treatment of retinoblastoma in preclinical models. Neuromolecular Med. 2009;11:43-52.

58. Lu L, Luo ST, Shi HS, et al. AAV2-mediated gene transfer of VEGFTrap with potent suppression of primary breast tumor growth and spontaneous pulmonary metastases by long-term expression. Oncol Rep. 2012;28:1332-1338.

59. Ling C, Lu Y, Cheng B, et al. High efficiency transduction of liver cancer cells by recombinant adeno-associated virus serotype 3 vectors. J Vis Exp. 2011;49:e2538.

60. Yuan L, Zhao H, Zhang L, Liu X. The efficacy of combination therapy using adeno-associated virus co-expression of apoptin and interleukin-24 on hepatocellular carcinoma. Tumour Biol. 2013;34:3027-3034.

61. Su H, Chang JC, Xu SM, Kan YW. Selective killing of AFP positive hepatocellular carcinoma cells by adeno-associated virus transfer of the herpes simplex virus thymidine kinase gene. Hum Gene Ther. 1996;7:463-470.

62. Steele JC, Di Pasquale G, Ramlogan CA, Patel V, Chiorini JA, Morris JC. Oral vaccination with adeno-associated virus vectors expressing the Neu inhibits the growth of murine breast cancer. Mol Ther. 2013;21:680-687.

63. Sun A, Tang J, Terranova PF, Zhang X, Thrasher JB, Li B. Adeno-associated virus-delivered short hairpin-structured RNA for androgen receptor gene silencing induces tumor eradication of prostate cancer xenografts in nude mice: a preclinical study. Int J Cancer. 2010;126:764-774.

64. Crommentuijn MH, Kantar R, Noske DP, et al. Systemically administered AAV9-sTRAIL combats invasive glioblastoma in a patient-derived orthotopic xenograft model. Mol Ther Oncolytics. 2016;3:16017. 
65. Zhen Z, Yang K, Ye L, You Z, Chen R, Liu Y. Decorin gene upregulation mediated by an adeno-associated virus vector increases intratumoral uptake of nab-paclitaxel in neuroblastoma via inhibition of stabilin-1. Invest New Drugs. Epub 2017 Jun 20.

66. Meshii N, Takahashi G, Okunaga S, et al. Enhancement of systemic tumor immunity for squamous cell carcinoma cells from oncolytic herpes simplex virus. Cancer Gene Ther. 2013;20:493-498.

67. Li H, Nakashima H, Decklever TD, Nace RA, Russell SJ. HSV-NIS, an oncolytic herpes simplex virus type 1 encoding the human sodium iodine symporter for preclinical prostate cancer radiovirotherapy. Cancer Gene Ther. 2013;20:478-485.

68. Chen CY, Wang PY, Hutzen B, et al. Cooperation of oncolytic herpes virotherapy and blockade in murine rhabdomyosarcoma models. Sci Rep. 2017;7:2396.

69. Yin L, Zhao C, Han J, et al. Antitumor effects of oncolytic herpes simplex virus type 2 against colorectal cancer in vitro and in vivo. Ther Clin Risk Manag. 2017;13:117-130.

70. Delwar ZM, Liu G, Kuo Y, et al. Tumour-specific triple-regulated oncolytic herpes virus to target glioma. Oncotarget. 2016;7:28658-28669.

71. Esaki S, Rabkin SD, Martuza RL, Wakimoto H. Transient fasting enhances replication of oncolytic herpes simplex virus in glioblastoma. Am J Cancer Res. 2016;6:300-311.

72. Khare PD, Liao S, Hirose Y, et al. Tumor growth suppression by a retroviral vector displaying scFv antibody to CEA and carrying the iNOS gene. Anticancer Res. 2002;22:2443-2446.

73. Li F, Guo Y, Han L, et al. In vitro and in vivo growth inhibition of drug-resistant ovarian carcinoma cells using a combination of cisplatin and a TRAIL-encoding retrovirus. Oncol Lett. 2012;4:1254-1258.

74. Schambach A, Morgan M. Retroviral vectors for cancer gene therapy. Recent Results Cancer Res. 2016;209:17-35.

75. Lu YC, Chen YJ, Yu YR, et al. Replicating retroviral vectors for oncolytic virotherapy of experimental hepatocellular carcinoma. Oncol Rep. 2012;28:21-26.

76. Logg CR, Robbins JM, Jolly DJ, Gruber HE, Kasahara N. Retroviral replicating vectors in cancer. Methods Enzymol. 2012;507:199-228.

77. Xiao L, Joo KI, Lim M, Wang P. Dendritic cell-directed vaccination with a lentivector PSCA for prostate cancer in mice. PLoS One. 2012; 7:e48866

78. Ravet L, Lulka H, Gross F, Casteilla L, Buscail L, Cordelier P. Using lentiviral vectors for efficient pancreatic cancer gene therapy. Cancer Gene Ther. 2010;17:315-324.

79. Zhang YW, Niu J, Lu X, et al. Multi-target lentivirus specific to hepatocellular carcinoma: in vitro and in vivo studies. J Hepatol. 2013;58: 502-508.

80. Chen YS, Li HR, Miao Y, et al. Local injection of lentivirus-delivered livin shRNA suppresses lung adenocarcinoma growth by inducing a G0/G1-phase cell cycle arrest. Int J Clin Exp Pathol. 2012;5:796-805.

81. Li R, Yang HQ, Hi HL, Feng S, Qin RH. Inhibition of CDH17 gene expression via RNA interference reduces proliferation and apoptosis of human MKN28 gastric cancer cells. Int J Oncol. 2017;50:15-22.

82. Yan F, Wang X, Zhu M, Hu X. RNAi-mediated downregulation of cyclin $\mathrm{Y}$ to attenuate human breast cancer cell growth. Oncol Rep. 2016;36: 2793-2799.

83. Tian L, Liu J, Xia GH, Chen BA. RNAi-mediated knockdown of MCM7 gene on CML cells and its therapeutic potential for leukemia. Med Oncol. 2017;34:21.

84. Yolamanova M, Meier C, Shaytan AK, et al. Peptide nanofibrils boost retroviral gene transfer and provide a rapid means for concentrating viruses. Nat Nanotechnol. 2013;8:130-136.

85. Ranzani M, Cesana D, Bartolomae CC, et al. Lentiviral vector-based insertional mutagenesis identifies genes associated with liver cancer. Nat Methods. 2013;10:155-161.

86. Uhlig KM, Schülke S, Scheuplein VA, et al. Lentiviral protein transfer vectors are an efficient vaccine platform and induce a strong antigenspecific cytotoxic T cell response. J Virol. 2015;89:9044-9060.
87. Liljeström $\mathrm{P}$, Garoff $\mathrm{H}$. A new generation of animal cell expression vectors based on the Semliki Forest virus replicon. Biotechnology (N Y). 1991;9:1356-1361.

88. Xiong, C, Levis R, Shen P, Schlesinger S, Rice CM, Huang HV. Sindbis virus: an efficient, broad host range vector for gene expression in animal cells. Science. 1989;243:1188-1191.

89. Davis NL, Willis LV, Smith JF, Johnston RE. In vitro synthesis of infectious Venezuelan equine encephalitis virus RNA from a cDNA clone: analysis of a viable deletion mutant. Virology. 1989;171:189-204.

90. Ying H, Zaks TZ, Wang RF, et al. Cancer therapy using a self-replicating RNA vaccine. Nat Med. 1999;5:823-827.

91. Murphy AM, Morris-Downes MM, Sheahan BJ,Atkins GJ. Inhibition of human lung carcinoma cell growth by apoptosis induction using Semliki Forest virus recombinant particles. Gene Ther. 2000;7:1477-1482.

92. Leitner WW, Hwang LN, deVeer MJ, et al. Alphavirus-based DNA vaccine breaks immunological tolerance by activating innate antiviral pathways. Nat Med. 2003;9:33-39.

93. Vähä-Koskela MJ, Kallio JP, Jansson LC, et al. Oncolytic capacity of attenuated replicative Semliki Forest virus in human melanoma xenografts in severe combined immunodeficient mice. Cancer Res. 2006;66:7185-7194.

94. Ketola A, Hinkkanen A, Yongabi F, et al. Oncolytic Semliki Forest virus vector as a novel candidate against unresectable osteosarcoma. Cancer Res. 2008;68:8342-8350.

95. Määttä AM, Mäkinen K, Ketola A, et al. Replication competent Semliki Forest virus prolongs survival in experimental lung cancer. Int $J$ Cancer. 2008;123:1704-1711.

96. Autio KP, Ruotsalainen JJ, Anttila MO et al. Attenuated Semliki Forest virus for cancer treatment in dogs: safety assessment in two laboratory beagles. BMC Vet Res. 2015;11:170.

97. Tseng JC, Levin B, Hurtado A et al. Systemic tumor targeting and killing by Sindbis viral vectors. Nat Biotechnol. 2004;22:70-77.

98. Rodriguez-Madoz JR, Prieto J, Smerdou C. Biodistribution and tumor infectivity of Semliki Forest virus vectors in mice: effects of re-administration. Mol Ther. 2007;15:2164-2171.

99. Lundstrom K, Boulikas T. Breakthrough in cancer therapy: encapsulation of drugs and viruses. Curr Drug Discov. 2002;11:19-23.

100. Ylösmäki E, Martikainen M, Hinkkanen A, Saksela K. Attenuation of Semliki Forest virus neurovirulence by microRNA-mediated detargeting. J Virol. 2013;87:335-344.

101. Lin Y, Zhang H, Liang J, et al. Identification and characterization of alphavirus M1 as a selective oncolytic virus targeting ZAP-defective human cancers. Proc Natl Acad Sci U S A. 2014;111:E4504-E4512.

102. Zhang $\mathrm{H}$, Lin $\mathrm{Y}$, Li K, et al. Naturally existing oncolytic virus M1 Is nonpathogenic for the nonhuman primates after multiple rounds of repeated intravenous injections. Hum Gene Ther. 2016;27:700-711.

103. Martikainen M, Ruotsalainen J, Tuomela J, et al. Oncolytic alphavirus SFV-VA7 efficiently eradicates subcutaneous and orthotopic human prostate tumours in mice. Br J Cancer. 2017;117:51-55.

104. Pijlman GP, Suhrbier A, Khromykh AA. Kunjin virus replicons: an RNA-based, non-cytopathic viral vector system for protein production, vaccine and gene therapy applications. Exp Opin Biol Ther. 2006;6:134-145.

105. Shi PY, Tilgner M, Lo MK. Construction and characterization of subgenomic replicons of New York strain of West Nile virus. Virology. 2002;296:219-233.

106. Molenkamp R, Kooi EA, Lucassen MA, et al. Yellow fever virus replicons as an expression system for hepatitis $\mathrm{C}$ virus structural proteins. J Virol. 2003;77:1644-1648.

107. Jones M, Davidson A, Hibbert L, et al. Dengue virus inhibits alpha interferon signaling by reducing STAT2 expression. $J$ Virol. 2005;79:5414-5420.

108. Gherke R, Ecker M, Aberle SW, Allison SL, Heinz FX, Mandl CW. Incorporation of tick-borne encephalitis virus replicons into viruslike particles by a packaging cell line. J Virol. 2003;77:8924-8933. 
109. Hoang-Le D, Smeenk L, Anraku I, et al. A Kunjin replicon vector encoding granulocyte macrophage colony-stimulating factor for intratumoral gene therapy. Gene Ther. 2009;16:190-199.

110. Osakada F, Callaway EM. Design and generation of recombinant rabies virus vectors. Nat Protoc. 2013;8:1583-1601.

111. Ito N, Takayama-Ito M, Yamada K, Hosokawa J, Sugiyama M, Minamoto N. Improved recovery of rabies virus from cloned cDNA using a vaccinia virus-free reverse genetics system. Microbiol Immunol. 2003;47:613-617.

112. An H, Kim GN, Kang CY. Genetically modified $\mathrm{VSV}_{\mathrm{NJ}}$ vector is capable of accommodating a large foreign gene insert and allows high level gene expression. Virus Res. 2013;171:168-177.

113. Murphy AM, Besmer DM, Moerdyk-Schauwecker M, et al. Vesicular stomatitis virus as an oncolytic agent against pancreatic ductal adenocarcinoma. J Virol. 2012;86:3073-3087.

114. Hastie E, Besmer DM, Shah NR, et al. Oncolytic vesicular stomatitis virus in an immunocompetent model of MUC1-positive of MUC1-null pancreatic ductal adenocarcinoma. J Virol. 2013;87:10283-10294.

115. Hastie E, Grdzelishvili VZ. Vesicular stomatitis virus as a flexible platform for oncolytic virotherapy against cancer. J Gen Virol. 2012;93:2529-2545.

116. Felt SA, Moerdyk-Schauwecker MJ, Grdzelishvili VZ. Induction of apoptosis in pancreatic cancer cells by vesicular stomatitis virus. Virology. 2015;474:163-173.

117. Le Boeuf F, Selman M, Son HH, et al. Oncolytic Maraba virus MG1 as a treatment for sarcoma. Int J Cancer. 2017;141:1257-1264.

118. Zhou Y, Wen F, Zhang P, Tang R, Li Q. Vesicular stomatitis virus is a potent agent for the treatment of malignant ascites. Oncol Rep. 2016;35:1573-1581

119. Radecke F, Spielhofer P, Schneider H, et al. Rescue of measles viruses from cloned DNA. EMBO J. 1995;14:5773-5784.

120. Msaouel P, Iankov ID, Dispenzieri A, Galanis E. Attenuated oncolytic measles virus strains as cancer therapeutics. Curr Pharm Biotechnol. 2012;13:1732-1741

121. Grote D, Russell SJ, Cornu TI, et al. Live attenuated measles virus induces regression of human lymphoma xenografts in immunodeficient mice. Blood. 2001;97:3746-3754.

122. Hasegawa K, Pham L, O’Connor MK, Federspiel MJ, Russell SJ, Peng KW. Dual therapy of ovarian cancer using measles viruses expressing carcinoembryonic antigen and sodium iodide symporter. Clin Cancer Res. 2006;12:1868-1875.

123. McDonald CJ, Erlichman C, Ingle JN, et al. A measles virus vaccine strain derivative as a novel oncolytic agent against breast cancer. Breast Cancer Res Treat. 2006;99:177-184.

124. Msaouel P, Iankov ID, Allen C, et al. Engineered measles virus as a novel oncolytic therapy against prostate cancer. Prostate. 2009;69:82-91.

125. Paraskevakou G, Allen C, Nakamura T, et al. Epidermal growth factor receptor (EGFR)-retargeted measles virus strains effectively target EGFR- or EGFRvIII expressing gliomas. Mol Ther. 2007;15:677-686.

126. Kleinlützum D, Hanauer JD, Muik A, et al. Enhancing the oncolytic activity of CD133-targeted measles virus: receptor extension or chimerism with vesicular stomatitis virus are most effective. Front Oncol. 2017;7:127

127. Veinalde R, Grossardt C, Hartmann L, et al. Oncolytic measles virus encoding interleukin-12 mediates potent antitumor effects through $\mathrm{T}$ cell activation. Oncoimmunology. 2017;6:e1285992.

128. Csatary LK, Moss RW, Beuth H, Töröcsik B, Szeberenyi J, Bakacs T. Beneficial treatment of patients with advanced cancer using a Newcastle disease virus vaccine (MHT-68/H). Anticancer Res. 1999;19:635-638.

129. Zhao L, Liu H. Newcastle disease virus: a promising agent for tumor immunotherapy. Clin Exp Pharmacol Physiol. 2012;39:725-730.

130. Niu Z, Bai F, Sun T, et al. Recombinant Newcastle disease virus expressing IL15 demonstrates promising antitumor efficiency in melanoma model. Technol Cancer Res Treat. 2015;14:607-615.
131. Chai Z, Zhang P, Fu F, et al. Oncolytic therapy of a recombinant Newcastle disease virus D90 strain for lung cancer. Virol J. 2014;11:84.

132. Kumar R, Tiwari AK, Chaturvedi U, et al. Velogenic Newcastle disease virus as an oncolytic virotherapeutics: in vitro characterization. Appl Biochem Biotechnol. 2012;167:2005-2022.

133. Wu Y, He J, An Y, et al. Recombinant Newcastle disease virus (NDV/ ANH-IL-2) expressing human IL-2 as a potential candidate suppresses growth of hepatoma therapy. J Pharmacol Sci. 2016;132:24-30.

134. Wu Y, He J, Geng J, et al. Recombinant Newcastle disease virus expressing human TRAIL as a potential candidate for hepatoma therapy. Eur J Pharmacol. 2017;802:85-92.

135. Cheng X, Wang W, Xu Q, et al. Genetic modification of oncolytic Newcastle disease virus for cancer therapy. J Virol. 2016;90:5343-5352.

136. Cassel WA, Murray DR. A ten-year follow-up on stage II malignant melanoma patients treated postsurgically with Newcastle disease virus oncolysate. Med Oncol Tumor Pharmacother. 1992;9:169-171.

137. Steiner HH, Bonsanto MM, Beckhove P, et al. Antitumor vaccination of patients with glioblastoma multiforme: a pilot study to assess feasibility, safety, and clinical benefit. J Clin Oncol. 2004;22: 4272-4281.

138. Herold-Mende C, Karcher J, Dyckhoff G, Schirrmacher V. Antitumor immunization of head and neck squamous cell carcinoma patients with a virus-modified autologous tumor cell vaccine. Adv Otorhinolaryngol. 2005;62:173-183.

139. Zeh HJ, Bartlett DL. Development of a replication-selective oncolytic poxvirus for the treatment of human cancers. Cancer Gene Ther. 2002;9:1001-1012.

140. Mastrangelo MJ, Lattime EC. Virotherapy clinical trials for regional disease: in situ immune modulation using recombinant poxvirus vectors. Cancer Gene Ther. 2002;9:1013-1021.

141. Chen B, Timiryasova TM, Haghighat P, et al. Low-dose vaccinia virus-mediated cytokine gene therapy of glioma. J Immunother. 2001;24:46-57.

142. Ehrig K, Kilinc MO, Chen NG, et al. Growth inhibition of different human colorectal cancer xenografts after a single intravenous injection of oncolytic vaccinia virus GLV-1h68. J Transl Med. 2013;11:79.

143. Chernichenko N, Linkov G, Li P, et al. Oncolytic vaccinia virus therapy of salivary gland carcinoma. JAMA Otolaryngol Head Neck Surg. 2013;139:173-182.

144. Haddad D, Chen N, Zhang Q, et al. A novel genetically modified vaccinia virus in experimental models is effective against a wide range of human cancers. Ann Surg Oncol. 2012;19 Suppl 3:S665-S674.

145. Binz E, Berchtold S, Beil J, et al. Chemovirotherapy of pancreatic adenocarcinoma by combining oncolytic vaccinia virus GLV-1h68 with nab-paclitaxel plus gemcitabine. Mol Ther Oncolytics. 2017;6:10-21.

146. Brun J, Mahoney DJ, Le Boeuf F, et al. Oncolytic vaccinia virus safely and effectively treats skin tumors in mouse models of xeroderma pigmentosum. Int J Cancer. 2013;132:726-731.

147. Mell LK, Brumund KT, Daniels GA, et al. Phase I trial of intravenous oncolytic vaccinia virus (GL-ONC1) with cisplatin and radiotherapy in patients with locoregionally advanced head and neck carcinoma. Clin Cancer Res. 2017;23:5696-5702.

148. Crainic R, Couderc T, Martin A, Wychowski C, Girard M, Horaud F. An insight into poliovirus biology. Adv Exp Med Biol. 1989;257:61-66.

149. Bradley S, Jakes AD, Harrington K, Pandha H, Melcher A, ErringtonMais F. Applications of coxsackievirus A21 in oncology. Oncolytic Virother. 2014;3:47-55.

150. Shafren DR, Au GG, Nguyen T, et al. Systemic therapy of malignant human melanoma tumors by a common cold-producing enterovirus, coxsackievirus A21. Clin Cancer Res. 2004;10:53-60.

151. Au GG, Lincz LF, Enno A, Shafren DR. Oncolytic coxsackievirus A21 as a novel therapy for multiple myeloma. Br J Haematol. 2007;137: 133-141.

152. Skelding KA, Barry RD, Shafren DR. Systemic targeting of metastatic human breast tumor xenografts by coxsackievirus A21. Breast Cancer Res Treat. 2009;113:21-30. 
153. Berry LJ, Au GG, Barry RD, et al. Potent oncolytic activity of human enteroviruses against human prostate cancer. Prostate. 2008;68:577-587.

154. Yee YW, Chan SH, Quah MY, Shafren DR. Oncolytic activity of coxsackievirus A21 (CAVATAK) in human lung cancer: a novel targeted anti-cancer strategy. Poster presented at: 14th World Conference on Lung Cancer; July 3-7, 2011; Amsterdam, Netherlands.

155. Breitbach CJ, De Silva NS, Falls TJ, et al. Targeting tumor vasculature with an oncolytic virus. Mol Ther. 2011;19:886-894.

156. Benencia F, Courreges MC, Conejo-Garcia JR, et al. Oncolytic HSV exerts direct antiangiogenic activity in ovarian carcinoma. Hum Gene Ther. 2005;16:765-778.

157. Breitbach CJ, Arulanandam R, De Silva N, et al. Oncolytic vaccinia virus disrupts tumor-associated vasculature in humans. Cancer Res 2013;73:1265-1275.

158. Zhang Z, Zou W, Wang J, et al. Suppression of tumor growth by oncolytic adenovirus-mediated delivery of an antiangiogenic gene, soluble Flt-1. Mol Ther. 2005;11:553-562.

159. Gholami S, Marano A, Chen NG, et al. A novel vaccinia virus with dual oncolytic and anti-angiogenic therapeutic effects against triplenegative breast cancer. Breast Cancer Res Treat. 2014;148:489-499.

160. Hou WZ, Chen H, Rojas J, Sampath P, Thorne SH. Oncolytic vaccinia virus demonstrates antiangiogenic effects mediated by targeting of VEGF. Int J Cancer. 2014;135:1238-1246.

161. Jha BK, Polyakova I, Kessler P, et al. Inhibition of RNase L and RNAdependent protein kinase (PKR) by sunitinib impairs antiviral innate immunity. J Biol Chem. 2011;286:26319-26326.

162. Jha BK, Dong B, Nguyen CT, Polyakova I, Silverman RH. Suppression of antiviral innate immunity by sunitinib enhances oncolytic virotherapy. Mol Ther. 2013;21:1749-1757.

163. Passaro C, Borriello F, Vastolo V, et al. The oncolytic virus d1922-947 reduces IL-8/CXCL8 and MCP-1/CCL2 expression and impairs angiogenesis and macrophage infiltration in anaplastic thyroid carcinoma. Oncotarget. 2016;7:1500-1515.

164. Taguchi S, Fukuhara H, Homma Y, Todo T. Current status of clinical trials assessing oncolytic virus therapy for urological cancers. Int $J$ Urol. 2017;24:342-351.

165. Burke JM, Lamm DL, Meng MV, et al. A first in human phase 1 study of CG0070, a GM-CSF expressing oncolytic adenovirus, for the treatment of nonmuscle invasive bladder cancer. J Urol. 2012;188:2391-2397.

166. Small EJ, Carducci MA, Burke JM, et al. A phase I trial of intravenous CG7870, a replication-selective, prostate-specific antigen-targeted oncolytic adenovirus, for the treatment of hormone-refractory, metastatic prostate cancer. Mol Ther. 2006;14:107-117.

167. Freytag SO, Khil M, Stricker H, et al. Phase I study of replicationcompetent adenovirus-mediated double suicide gene therapy for the treatment of locally recurrent prostate cancer. Cancer Res. 2002;62:4968-4976.

168. Pecora AL, Rizvi N, Cohen GI, et al. Phase I trial of intravenous administration of PV701, an oncolytic virus, in patients with advanced solid cancers. J Clin Oncol. 2002;20:2251-2266.

169. Park BH, Hwang T, Liu TC, et al. Use of a targeted oncolytic poxvirus, JX-594, in patients with refractory primary or metastatic liver cancer: a phase I trial. Lancet Oncol. 2008;9:533-542.

170. Kim SG, Hwang TH. Phase 2 trial of Pexa-Vec (pexastimogene devacirepvec; JX-594), an oncolytic and immunotherapeutic vaccinia virus, in patients with metastatic, refractory renal cell carcinoma (RCC). Eur $J$ Cancer. 2015;51:S510.

171. Gomella LG, Mastrangelo MJ, McCue PA, Maguire HC, Mulholland $\mathrm{SG}$, Lattime EC. Phase 1 study of intravesical vaccinia virus as a vector for gene therapy of bladder cancer. J Urol. 2001;166:1291-1295.

172. Gulley JL, Heery CR, Madan RA, et al. Phase I study of intraprostatic vaccine administration in men with locally recurrent or progressive prostate cancer. Cancer Immunol Immunother. 2013;62:1521-1531.

173. Vidal L, Pandha HS, Yap TA, et al. A phase I study of intravenous oncolytic reovirus type 3 Dearing in patients with advanced cancer. Clin Cancer Res. 2008;14:7127-7137.
174. Noonan AM, Farren MR, Geyer SM, et al. Randomized phase 2 trial of the oncolytic virus pelareorep (Reolysin) in upfront treatment of metastatic pancreatic adenocarcinoma. Mol Ther. 2016;24: 1150-1158.

175. Galanis E, Markovic SN, Suman VJ, et al. Phase II trial of intravenous administration of Reolysin (reovirus serotype-3-dearing strain) in patients with metastatic melanoma. Mol Ther. 2012;20: 1998-2003.

176. Karapanaglotou EM, Roulstone V, Twigger K, et al. Phase I/II trial of carboplatin and paclitaxel chemotherapy in combination with intravenous oncolytic reovirus in patients with advanced malignancies. Clin Cancer Res. 2012;18:2080-2089.

177. Patel DM, Foreman PM, Nabors LB, Riley K, Gillespie Y, Markert J. Design of a phase I clinical trial to evaluate M032, a genetically engineered HSV-1 expressing IL-12, in patients with recurrent/progressive glioblastoma multiforme, anaplastic astrocytoma, or gliosarcoma. Hum Gene Ther Clin Dev. 2016;27:69-78.

178. Roth JC, Cassady KA, Cody JJ, et al. Evaluation of the safety and biodistribution of M032 an attenuated herpes simplex virus type 1 expressing hIL-12 after intracerebral administration of Aotus nonhuman primates. Hum Gene Ther Clin Dev. 2014;25:16-27.

179. Markert JM, Razdan SN, Kuo HC, et al. A phase 1 trial of oncolytic HSV-1, G207, given in combination with radiation for recurrent GBM demonstrates safety and radiographic responses. Mol Ther. 2014;22:1048-1055.

180. Markert JM, Liechty PG, Wang W, et al. Phase 1B trial of mutant herpes simplex virus G207 inoculated pre- and post-tumor resection for recurrent GBM. Mol Ther. 2009;17:199-207.

181. Slovin SF, Kehoe M, Durso R, et al. A phase I dose escalation trial of vaccine replicon particles (VRP) expressing prostate-specific membrane antigen (PSMA) in subjects with prostate cancer. Vaccine. 2013;31:943-949.

182. Pandha H, Harrington K, Ralph C, Melcher A, Grose M, Shafren D. Phase I/II storm study: intravenous delivery of a novel oncolytic immunotherapy agent, coxsackievirus A21, in advanced cancer patients. J Immunother Cancer. 2015;3:P341.

183. Andtbacka RH, Curti BD, Hallmeyer S, et al. Phase II calm extension study: coxsackievirus A21 delivered intratumorally to patients with advanced melanoma induces immune-cell infiltration in the tumor microenvironment. J Immunother Cancer. 2015;3:P343.

184. Silk AW, Kaufman H, Gabriel N, et al. Phase 1B study of intratumoral coxsackievirus A21 (CVA21) and systemic pembrolizumab in advanced melanoma patients: interim results of the CAPRA clinical trial. Cancer Res. 2017;77:CT026.

185. Räty JK, Pikkarainen JT, Wirth T et al. Gene therapy: the first approved gene-based medicines, molecular mechanisms and clinical indications. Curr Mol Pharmacol. 2008;1:13-23.

186. Liu TC, Kim D. Gene therapy progress and prospects cancer: oncolytic viruses. Gene Ther. 2008;15:877-884.

187. Fukuhara H, Ino Y, Todo T. Oncolytic virus therapy: a new era of cancer treatment at dawn. Cancer Sci. 2016;107:1373-1379.

188. Kaufman HL, Kim DW, DeRaffele G, Mitcham J, Coffin RS, KimSchulze S. Local and distant immunity induced by intralesional vaccination with an oncolytic herpes virus encoding GM-CSF in patients with stage IIIC and IV melanoma. Ann Surg Oncol. 2010;17:718-730.

189. Heo J, Reid T, Ruo L, et al. Randomized dose-finding clinical trial of oncolytic immunotherapeutic vaccinia JX-594 in liver cancer. Nat Med. 2013;19:329-336.

190. Ino Y, Todo T. Clinical development of a third-generation HSV-1 (G478) for malignant glioma. Gene Ther Regul. 2010;5:101-111.

191. Ramesh N, Ge Y, Ennist DL, et al. CG0070, a conditionally replicating granulocyte macrophage colony-stimulating factor-armed oncolytic adenovirus for the treatment of bladder cancer. Clin Cancer Res. 2006;12:305-313.

192. Gollamudi R, Ghalib MH, Desai KK, et al. Intravenous administration of Reolysin, a live replication competent RNA virus is safe in patients in advanced solid tumors. Invest New Drugs. 2010;28:641-649. 


\section{Publish your work in this journal}

Biologics: Targets and Therapy is an international, peer-reviewed journal focusing on the patho-physiological rationale for and clinical application of Biologic agents in the management of autoimmune diseases, cancers or other pathologies where a molecular target can be identified. This journal is indexed on PubMed Central, EMBase, and Scopus.
The manuscript management system is completely online and includes a very quick and fair peer-review system, which is all easy to use. Visit http://www.dovepress.com/testimonials.php to read real quotes from published authors.

Submit your manuscript here: https://www.dovepress.com/biologics-targets-and-therapy-journal 